\title{
Metalloproteinases and Their Associated Genes Contribute to the Functional Integrity and Noise-Induced Damage in the Cochlear Sensory Epithelium
}

\author{
Bo Hua Hu, ${ }^{1}$ Qunfeng Cai, ${ }^{1}$ Zihua Hu, ${ }^{2}$ Minal Patel,,${ }^{1}$ Jonathan Bard, ${ }^{3}$ Jennifer Jamison, ${ }^{3}$ and Donald Coling ${ }^{1}$ \\ ${ }^{1}$ Center for Hearing and Deafness, ${ }^{2}$ Center for Computational Research, New York State Center of Excellence in Bioinformatics and Life Sciences, \\ Departments of Ophthalmology, Biostatistics, and Medicine, State University of New York Eye Institute, and ${ }^{3}$ Next-Generation Sequencing and Expression \\ Analysis Core, Center of Excellence in Bioinformatics and Life Sciences, State University of New York at Buffalo, Buffalo, New York 14214
}

\begin{abstract}
Matrix metalloproteinases (MMPs) and their related gene products regulate essential cellular functions. An imbalance in MMPs has been implicated in various neurological disorders, including traumatic injuries. Here, we report a role for MMPs and their related gene products in the modulation of cochlear responses to acoustic trauma in rats. The normal cochlea was shown to be enriched in MMP enzymatic activity, and this activity was reduced in a time-dependent manner after traumatic noise injury. The analysis of gene expression by RNA sequencing and qRT-PCR revealed the differential expression of MMPs and their related genes between functionally specialized regions of the sensory epithelium. The expression of these genes was dynamically regulated between the acute and chronic phases of noise-induced hearing loss. Moreover, noise-induced expression changes in two endogenous MMP inhibitors, Timp1 and Timp2, in sensory cells were dependent on the stage of nuclear condensation, suggesting a specific role for MMP activity in sensory cell apoptosis. A short-term application of doxycycline, a broad-spectrum inhibitor of MMPs, before noise exposure reduced noise-induced hearing loss and sensory cell death. In contrast, a $7 \mathrm{~d}$ treatment compromised hearing sensitivity and potentiated noise-induced hearing loss. This detrimental effect of the long-term inhibition of MMPs on noise-induced hearing loss was further confirmed using targeted Mmp7 knock-out mice. Together, these observations suggest that MMPs and their related genes participate in the regulation of cochlear responses to acoustic overstimulation and that the modulation of MMP activity can serve as a novel therapeutic target for the reduction of noise-induced cochlear damage.
\end{abstract}

\section{Introduction}

Matrix metalloproteinases (MMPs) are a family of potent endopeptidases that collectively have the ability to degrade all components of the extracellular matrix (ECM) (Birkedal-Hansen et al., 1993; Ravanti and Kahari, 2000; Page-McCaw et al., 2007; Consolo et al., 2009). The MMP family includes collagenases, gelatinases, stromelysins, matrilysins, and other proteinases with specialized compartmentalization and substrate specificity. Thus far, at least 24 murine and 23 human MMPs have been characterized (Yong, 2005; Page-McCaw et al., 2007). Together with the tissue inhibitors of metalloproteinases (TIMPs) and related genes, MMPs are the major physiological regulators of the turnover of the ECM (Page-McCaw et al., 2007) and are responsible for the remodeling of the ECM associated with tissue morphogenesis and wound healing. MMPs also interact with other sub-

\footnotetext{
Received March 24, 2012; revised Aug. 16, 2012; accepted Aug. 22, 2012.

Author contributions: B.H.H. designed research;B.H.H., Q.C., M.P., and J.J. performed research; B.H.H., Q.C., Z.H., M.P., J.B., and D.C. analyzed data; B.H.H. wrote the paper.

This work was supported by National Institute on Deafness and Other Communication Disorders Grant 5R01DC010154-02.

The authors declare no competing financial interests.

Correspondence should be addressed to Dr. Bo Hua Hu, Center for Hearing and Deafness, State University of New York at Buffalo, 137 Cary Hall, 3435 Main Street, Buffalo, NY 14214. E-mail: bhu@buffalo.edu.

DOI:10.1523/JNEUROSCI.1588-12.2012

Copyright $\odot 2012$ the authors $\quad 0270-6474 / 12 / 3214927-15 \$ 15.00 / 0$
}

strate molecules, including growth factors and adhesion molecules (McCawley and Matrisian, 2001), and participate in a variety of essential cellular processes, including cell proliferation, migration, survival or apoptosis, inflammation, and synaptic remodeling (Sternlicht and Werb, 2001; Parks et al., 2004; Fredrich and Illing, 2010).

Exposure to intense noise is a common cause of sensory hearing loss in the adult population. Noise exposure causes structural damage to the cochlear sensory epithelium, particularly to its sensory cells. Although the functional and pathological impacts of acoustic trauma have been thoroughly documented (Saunders et al., 1985; Raphael and Altschuler, 1991; Raphael et al., 1993; Henderson et al., 2006; Bohne et al., 2007; Hu, 2012), the molecular mechanisms responsible for these functional and structural changes remain elusive.

The cochlear sensory epithelium, which contains sensory cells and supporting cells, is organized through ECM and cellcell junctions (Gulley and Reese, 1976; Tsuprun and Santi, 1999). The maintenance of ECM homeostasis has been shown to be important for inner ear development (Davies et al., 2007; Szabova et al., 2010), and the dysregulation of this structure leads to sensorineural hearing loss (Gratton et al., 2005; Kundu et al., 2009; Nam et al., 2011; Setz et al., 2011). In noise-traumatized cochleae, morphological changes in ECM structures have been documented (Canlon, 1987, 1988). 
Changes in the expression of adhesion-related genes have also been documented in noise-traumatized cochleae (Raphael et al., 1988; Cai et al., 2012). Moreover, apoptotic sensory cell death has been implicated in cochlear pathogenesis (Hu et al., 2000; Wang et al., 2002; Ylikoski et al., 2002; Niu et al., 2003; Shibuya et al., 2003; Han et al., 2006). Because many ECM-, adhesion-, and apoptosis-related molecules are targets of MMPs, we hypothesized that MMPs contribute to noiseinduced cochlear damage. Thus far, the information regarding the expression profile of MMPs and their related genes in the normal cochlear sensory epithelium and their roles in cochlear pathogenesis after acoustic trauma is still not clear.

The current study was designed to determine the role of MMPs in the modulation of cochlear responses to acoustic trauma. For the first time, we establish a link between MMPs and acute acoustic cochlear injury. Our study suggests that MMP modulation may serve as a novel therapeutic strategy for the reduction of noise-induced cochlear damage.

\section{Materials and Methods}

Animals. Young Sasco Sprague Dawley rats (2-4 months old, male and female; Charles River Laboratories), Mmp7 knock-out mice (B6.129$\mathrm{Mmp} 7^{\mathrm{tm} 1 \mathrm{Lmm}} / \mathrm{J}, 8-12$ weeks old, male and female; The Jackson Laboratory), and C57BL/6J (8-12 weeks old, male and female; The Jackson Laboratory) were used. B6.129-Mmp $7^{\mathrm{tm} 1 \mathrm{Lmm}} / \mathrm{J}$ mice were congenic on a C57BL/6J background. All animals received a baseline-hearing evaluation. Only the subjects that exhibited normal hearing sensitivity were included in the study. The procedures involving the use and care of the animals were approved by the Institutional Animal Care and Use Committee of the State University of New York at Buffalo.

Experimental procedures. After the baseline-hearing evaluation, the animals were randomly assigned to either one of the noise groups or one of the control groups. The animals in the noise groups received a noise exposure and scheduled hearing evaluations. Their cochleae were collected for gene expression analyses and pathological analysis at defined time points. The control animals underwent a protocol identical to that of the subjects in the corresponding noise groups except for the noise exposure. A portion of the animals from both groups was treated with doxycycline to inhibit MMP activity or with vehicle. These animals received hearing evaluations before and after the doxycycline treatment and were either killed after the completion of the doxycycline treatment or further exposed to noise and then killed at a defined time point. The control group for this set of experiments received a physiological saline solution, the vehicle solution for the preparation of the doxycycline solution. The numbers of animals or cochleae used for each set of experimental conditions will be described in the subsequent sections, as well as in Results. The separate experimental procedures are detailed below.

The experiments were performed by several observers, and the observers were not blinded to the experimental conditions. All data were objective measures and were analyzed independently by two researchers. All experimental groups had corresponding controls, and animals were randomly assigned to these experimental and control groups. There were no deaths attributable to attrition, and no data were excluded from analysis.

Noise exposure. A continuous noise (1-7 kHz) at $120 \mathrm{~dB}$ (sound pressure level, $\sim 20 \mu \mathrm{Pa}$ ) for $2 \mathrm{~h}$ was used to traumatize the cochlea. The noise signal was generated using a real-time signal processor [RP2.1; Tucker Davis Technologies (TDT)]. The signal was routed through an attenuator (PA5; TDT) and a power amplifier (Crown XLS 202; Harman International) to a loudspeaker (NSD2005-8; Eminence) positioned $30 \mathrm{~cm}$ above the animal's head. The noise level at the position of the animal's head in the sound field was calibrated using a sound level meter [model 800 B; Larson Davis, PCB Piezotronics Division (LD-PCB)], a preamplifier (model 825; LD-PCB), and a condenser microphone (LDL 2559; LD-PCB). The rats were individually exposed to the noise in a holding cage. This noise paradigm was used in our previous investigation $(\mathrm{Hu}$ and Cai, 2010; Cai et al., 2012) and is able to generate sensory cell damage and cochlear functional loss.

Suppression of MMP activity. To determine the role of MMPs in maintaining normal cochlear function and altering cochlear pathogenesis after noise exposure, we inhibited cochlear MMP activity using doxycycline hyclate (D9891; Sigma-Aldrich), a broad-spectrum inhibitor of MMPs (Burggraf et al., 2007; Bedi et al., 2010). The doxycycline solution $(25 \mathrm{mg} / \mathrm{ml})$ was freshly prepared each day by the dissolution of the drug in $0.9 \%$ saline. The solution was protected from light before use and was administrated by gavage twice daily (8:00 A.M. and 6:00 P.M.). Three dosages were used: (1) $50 \mathrm{mg} \cdot \mathrm{kg}^{-1} \cdot \mathrm{d}^{-1}$ for $1.5 \mathrm{~d}$ (three applications); (2) $50 \mathrm{mg} \cdot \mathrm{kg}^{-1} \cdot \mathrm{d}^{-1}$ for $7 \mathrm{~d}$; and (3) $100 \mathrm{mg} \cdot \mathrm{kg}^{-1} \cdot \mathrm{d}^{-1}$ for $7 \mathrm{~d}$. This dose range has been used in previous investigations in rat models and has been proven to be effective for the inhibition of MMP activity and/or expression (Canlon, 1988; Curci et al., 1998). The control animals received the same volume of $0.9 \%$ saline solution with an identical application paradigm.

Auditory brainstem responses. Auditory brain response (ABR) measurements were conducted before noise exposure and at multiple time points after noise exposure, as well as before, during, and multiple time points after doxycycline treatment (for the details of the test schedule, see Results) to determine the hearing sensitivity of the animals. The ABRs were recorded as described previously (Hu et al., 2009). Briefly, an animal was anesthetized with an intraperitoneal injection of a mixture of ketamine $(87 \mathrm{mg} / \mathrm{kg})$ and xylazine $(3 \mathrm{mg} / \mathrm{kg})$. The body temperature was maintained at $37.5^{\circ} \mathrm{C}$ with a warming blanket (Homeothermic Blanket Control Unit; Harvard Apparatus). Stainless-steel needle electrodes were placed subdermally over the vertex (non-inverting input) and posterior to the stimulated and nonstimulated ears (inverting input and ground) of the animal. The ABRs were elicited with tone bursts at 5, 10, 20,30, and $40 \mathrm{kHz}(0.5 \mathrm{~ms}$ rise/fall Blackman ramp, $1 \mathrm{~ms}$ duration, alternating phase) at the rate of $21 / \mathrm{s}$, which were generated digitally (SigGen; TDT) using a digital-to-analog converter (100 kHz sampling rate; RP2.1; TDT) and fed to a programmable attenuator (PA5; TDT), an amplifier (SA1; TDT), and a closed-field loudspeaker (CF1; TDT). The electrode outputs were delivered to a preamplifier/base station (RA4LI and RA4PA/RA16B; TDT). The responses were filtered $(100-3000 \mathrm{~Hz})$, amplified, and averaged using TDT hardware and software. These responses were then stored and displayed on a computer. The ABR threshold was defined as the lowest intensity that reliably elicited a detectable response.

Cochlear tissue collection. The animals were decapitated under deep anesthesia with $\mathrm{CO}_{2}$. The cochleae were quickly removed from the skull. For the analysis of the transcriptional expression patterns of MMPs and their related genes, the cochleae were perfused with an RNA stabilization reagent (RNAlater; Qiagen) and were dissected in the same reagent to collect the cochlear sensory epithelia. For the assessment of MMP activity, the cochleae were dissected in ice-cold PBS to collect the cochlear tissues containing the sensory epithelium and the lateral wall. For the immunohistological and pathological examinations, the cochleae were fixed with $10 \%$ buffered Formalin for at least $4 \mathrm{~h}$. The cochleae were then dissected in PBS, and the organs of Corti were collected.

RNA sequencing. The cochlear sensory epithelia from the two cochleae of one animal were pooled to generated one sample. Three biological repeats were performed. The total RNA was extracted from the tissues using the Qiagen RNeasy Micro kit as per the protocol of the manufacturer. The quality and quantity of collected total RNA was evaluated using the Agilent Bioanalyzer 2100 (Agilent Technologies) and the RiboGreen Quantification assay (Invitrogen).

The synthesis of cDNA from 8-10 ng of total RNA per sample was performed with the Clontech SMARTerTM Ultra Low RNA kit. From each cDNA sample, a sequencing library was prepared using the Illumina Paired End Sample Prep kit (Illumina) according to the Illumina Ultra Low Input mRNA-Seq Protocol. The average insert size of the libraries was 124 bp. Each cDNA library was sequenced in a 50 cycle single read flow cell lane on an Illumina HiSeq 2000.

$q R T-P C R$ array. We assessed the gene expression levels of $20 \mathrm{MMPs}$ and their related genes (for the gene list, see Table 2) using the PARN013A Biosciences adhesion array (Qiagen). The animals were killed, and the cochleae were collected at a defined time point (control, $2 \mathrm{~h}, 1 \mathrm{~d}$, or 
$28 \mathrm{~d}$ after noise exposure). After the dissection of the cochlea, the apical and basal sections of the sensory epithelium were collected separately. The apical sample contained the apical $45 \%$ of the sensory epithelium, and the basal sample contained the tissue corresponding to $45-90 \%$ from the apex of the sensory epithelium. Each sample was analyzed separately using qRT-PCR. Four biological repetitions from four subjects were performed for the control group as well as for the $2 \mathrm{~h}$ and $1 \mathrm{~d}$ post-noise groups. Three biological repetitions were performed for the $28 \mathrm{~d}$ postnoise group.

The protocol to isolate the total RNA, synthesize and preamplify the cDNA, and run the qRT-PCR reactions was performed as described previously (Cai et al., 2012). The total RNA was isolated from each sample using the RNeasy Micro kit (Qiagen) as per the instructions of the manufacturer. The concentration of isolated total RNA was measured with a NanoDrop instrument (NanoDrop 1000; Thermo Fisher Scientific). The isolated total RNA was used to generate CDNA, and the CDNA was preamplified using the RT ${ }^{2}$ Nano PreAMP cDNA Synthesis kit (Qiagen). The synthesized cDNA was mixed with $\mathrm{RT}^{2}$ Real-Time PCR SYBR Green/Fluorescein Master Mix (Qiagen), transferred to a 96-well plate, and used to perform qRT-PCR on a Bio-Rad MyiQ Single-Color RealTime PCR System. The quality control for the mRNA quantification was performed using three integrated control assays in the PCR array: a reverse transcription control, a positive PCR control, and a genomic DNA control. All PCR runs passed the control tests.

Individual $m R N A$ expression analysis. To determine the effect of MMP inhibition on MMP expression, we examined the transcriptional expression of Mmp7, Mmp9, Mmp11, Mmp13, and Mmp14 using individual qRT-PCR with pre-developed TaqMan gene expression primer/probe assays (Applied Biosystems). After completion of the doxycycline treatment $\left(50 \mathrm{mg} \cdot \mathrm{kg}^{-1} \cdot \mathrm{d}^{-1}\right)$ for $7 \mathrm{~d}$, the animals were killed. One cochlea, either the right or the left, was dissected to collect the sensory epithelium. The sensory epithelium from one cochlea was used to generate one sample, and five repetitions from five individual subjects were conducted for each experimental condition (doxycycline-treated and saline-treated).

The isolated total RNAs were reverse transcribed using a high-capacity cDNA reverse transcription kit (Applied Biosystems). qRT-PCR was performed on a MyIQ two-color real-time PCR detection system (Bio-Rad). Pre-developed Hprt1, Rplp1, and Actb gene expression assays (Applied Biosystems) were used as endogenous controls.

Immunohistology. Immunohistochemistry was used to examine the expression changes in the Timp1 and Timp2 proteins as well as the expression change in Bax protein in the organ of Corti. The animals were killed at $2 \mathrm{~h}$ after noise exposure. The cochleae were fixed with $10 \%$ buffered Formalin for $4 \mathrm{~h}$. After dissection in $10 \mathrm{~mm}$ PBS, the organs of Corti were collected. The tissues were then permeabilized with $0.2 \%$ Triton X-100 in PBS for 30 min, blocked with 10\% goat serum in PBS, and incubated overnight at $4^{\circ} \mathrm{C}$ with the requisite primary antibody (Timp1, sc-5538, Santa Cruz Biotechnology; Timp2, C0348, Assay Biotechnology Company; Bax, ab-3192, Abcam) at a concentration recommended by the manufacturers. The tissues were then rinsed with PBS (three times), incubated with a secondary antibody (Alexa Fluor 488labeled goat anti-rabbit antibody for Timp1 and Timp2, Invitrogen; FITC-conjugated goat anti-rat IgG for Bax, R40401, Caltag Laboratories) for $2 \mathrm{~h}$, and counterstained with propidium iodide ( $5 \mu \mathrm{g} / \mathrm{ml}$ in PBS) for $10 \mathrm{~min}$.

For the noise groups, 6, 10, and 3 cochleae were used for Timp1, Timp2, and Bax staining, respectively. The cochleae from six additional animals that did not undergo noise exposure were used as the normal control. Several pieces of the organs of Corti from these cochleae were stained with only the secondary antibodies to assess nonspecific staining.

The immunolabeled tissues were first inspected with a microscope equipped with epifluorescence illumination to identify sensory cell lesions. The lesions were further examined with confocal microscopy (Carl Zeiss LSM510 multichannel laser scanning confocal imaging system) using a method that has been reported previously (Hu and Cai, 2010; Cai et al., 2012). In the current investigation, we did not compare the intensity of immunolabeling among the tissues from different cochleae because of the potential influence of technical variations associated with the tissue preparation, staining, and evaluation. Instead, we focused on the detection of staining differences within individual tissues, because tissues presumably received identical treatment for the immunolabeling. The staining intensity was visually examined. If sensory cells exhibited a detectable increase in the staining intensity compared with the staining in their neighboring sensory cells, we considered these cells to be positively stained cells. The numbers of these positive cells were counted for additional quantitative analysis.

MMP activity. The MMP activities in the cochlear tissues were evaluated using a fluorometric MMP assay kit (SensoLyte 520 generic MMP assay kit; AnaSpec). The supplied substrate is a fluorescence resonant energy transfer (FRET) peptide conjugated with 5-carboxyfluorescein and the QXL520 quencher as a FRET pair. The substrate was designed to detect the activity of a variety of human MMPs, including Mmp1, Mmp2, Mmp7, Mmp8, Mmp9, Mmp12, and Mmp14. The animals were killed at either $2 \mathrm{~h}(n=5)$ or $1 \mathrm{~d}(n=5)$ after noise exposure or at the time of the completion of a $7 \mathrm{~d}$ doxycycline treatment $\left(50 \mathrm{mg} \cdot \mathrm{kg}^{-1} \cdot \mathrm{d}^{-1}, n=5\right)$. For all experimental conditions, an equal number of control animals received only the saline treatment.

The animals were killed, and the cochleae were dissected in ice-cold 10 mм PBS. The cochlear tissues containing the sensory epithelium and the lateral wall were collected. The tissues from one cochlea were used to generate one sample. We also collected tissues from the kidney cortex $(n=5)$ and the inferior colliculus of the brainstem $(n=5)$ from normal control subjects. Each sample was homogenized in the assay buffer (provided by the manufacturer) containing $0.1 \%(\mathrm{v} / \mathrm{v})$ Triton X-100 and then centrifuged at $10,000 \times g$ at $4^{\circ} \mathrm{C}$ for $15 \mathrm{~min}$. The supernatant was collected, and the protein concentration was measured using a spectrophotometer (NanoDrop 1000; Thermo Fisher Scientific). The samples were stored at $-70^{\circ} \mathrm{C}$ before the measurement of MMP activity.

To assess the MMP activity, $1 \mu \mathrm{l}$ of 4 -aminophenylmercuric acetate ( $50 \mathrm{~mm}$ ) was added to $49 \mu \mathrm{l}$ of a sample containing $200 \mu \mathrm{g}$ of protein to activate the pro-MMPs. The sample was incubated at $37^{\circ} \mathrm{C}$ for $3 \mathrm{~h}$. Then $50 \mu \mathrm{l}$ of the MMP substrate was added to the sample and was mixed by shaking gently for $30 \mathrm{~s}$. The sample fluorescence intensity was measured every $5 \mathrm{~min}$ for a period of $60 \mathrm{~min}$ using a microplate reader (Bio-Tek Multifunction Plate Reader; BioTek Instruments) with excitation at 490 $\mathrm{nm}$ and emission at $520 \mathrm{~nm}$. We used a substrate control that contained only the assay buffer as the background control. The fluorescence reading from this background control was used to normalize the sample readings to obtain the relative fluorescence units (RFUs). The RFU was then normalized using the total protein concentration for each sample.

Assessment of sensory cell damage. The organs of Corti were collected for pathological examination at $28 \mathrm{~d}$ after exposure or at $28 \mathrm{~d}$ after doxycycline treatment. The animals were killed, and the cochleae were fixed with $10 \%$ buffered Formalin. After dissection, the organs of Corti were collected and stained with a propidium iodide solution ( $5 \mu \mathrm{g} / \mathrm{ml}$ in PBS) for $10 \mathrm{~min}$. The tissues were mounted on slides with anti-fade medium (Prolong Gold anti-fade reagent; Invitrogen).

The specimens were examined with a microscope equipped with epifluorescence illumination to identify hair cell lesions. The pathological criteria used to identify the damaged cells were similar to the method described previously (Hu et al., 2002; Yang et al., 2004). The cells with malformed nuclei (condensed, fragmented, or swollen) were considered damaged cells. Based on the nuclear morphology, the number of damaged and missing hair cells was quantified for each cochlea. The average numbers for each experimental condition were assembled into a cochleogram showing the frequency-place correlation for the rat (Müller, 1991).

Data analyses. The average ABR thresholds obtained before and after noise exposure and before and after doxycycline treatment were compared using a two-way ANOVA with two factors of either time $\times$ frequency or treatment $\times$ time (for details, see Results). For the quantification of the cochlear damage induced by noise exposure or by doxycycline treatment, the average numbers of missing cells among different experimental groups were compared using a one-way ANOVA. If a significant main effect occurred, post hoc testing with the Tukey's test, the Bonferroni's test, or the Kruskal-Wallis test was performed to delineate the nature of the differences (for details, see Results).

For the RNA-sequencing (RNA-seq) data analysis, the sequence results were aligned to the rat reference genome sequence (University of 
California, Santa Cruz Genome Browser, Rn4) (Fujita et al., 2011) using TopHat version 1.3.2 (Trapnell et al., 2009) and Bowtie (Langmead et al., 2009). The resulting alignments were further assembled and annotated using Cufflinks (Trapnell et al., 2010). The abundance of the gene expression was normalized to the reads per kilobase of exon model per million mapped reads (RPKM) (Mortazavi et al., 2008).

For the analysis of the changes in expression of the MMPs and their related genes, a relative quantification method was used (Livak and Schmittgen, 2001; Stankovic and Corfas, 2003). We first examined the expression levels of five reference genes (Rplp1, Hprt1, Rpl13a, $L d h a$, and $A c t b)$ to select stable genes for the normalization of gene expression. All of the genes are highly expressed in normal and noise-damaged cochlear sensory epithelia. Four genes (Hprt1, Rplp1, Rpl13a, and Actb) were stably expressed, with fold changes $\leq 1.5$ at $2 \mathrm{~h}$ and $1 \mathrm{~d}$ after noise exposure. Therefore, we selected Rplp1, Hprt1, Rpl13a, and Actb for the qRT-PCR array data analysis, Hprt1, Rplp1, and Actb for the individual qRT-PCR data analysis of doxycycline-treated cochlear samples, and Actb for the qRT-PCR data analysis of $M m p 7^{-1-}$ and wild-type mouse samples.

The expression level of a given gene was first normalized to the average level of the reference genes to generate the $\Delta \mathrm{Ct}$ value. The $\Delta \Delta \mathrm{Ct}$ was then calculated with the following formula: $\Delta \mathrm{Ct}$ (an experimental group) $\Delta \mathrm{Ct}$ (a control group). The significance of the changes for qRT-PCR array data was analyzed using significance analysis of microarrays (SAM) (Tusher et al., 2001) with the number of permutations equal to 100 . The significance of the changes for the individual qRT-PCR data was analyzed using Student's $t$ test. An expression change was considered significant if the false discovery rate (FDR) was $\leq 6.2 \%$, and the fold difference was $\geq 2$. A Pearson's analysis was used to define the correlation of the expression levels of the MMPs and their related genes between the samples from the apical and basal sections of the cochlear sensory epithelium.

The comparison of the MMP activities of the tissues from the cochlea, brain, and kidney was achieved using one-way ANOVA with the post hoc Tukey's test. The comparisons of the MMP activities between the noisetraumatized cochleae and the control cochleae and between the cochleae treated with doxycycline and those treated with saline were performed using Student's $t$ test.

For the analysis of Timp1 and Timp2 immunoreactivity, we examined the sensory epithelium to identify the positively stained sensory cells. Positive cells were defined by a marked increase in immunoreactivity compared with the neighboring sensory cells. The numbers of Timp1and Timp2-positive cells were quantified for each cochlea. The ratio of the number of positively stained cells to the number of cells that exhibited nuclear malformation (fragmented or condensed) was calculated.

\section{Results}

\section{Acoustic overstimulation causes a time-dependent change in} cochlear MMP activity

To determine the role of MMPs in noise-induced cochlear pathogenesis, we examined the MMP activity in normal and noisetraumatized rat cochleae. In normal cochleae, we detected strong MMP activity (Fig. 1A). To provide a context for the assessment of MMP activity in the cochlea, we also examined the MMP activity in the brain and kidney. We found that the MMP activity in the cochlea was comparable with that observed in the kidney. In both tissues, the activity was stronger than that in brain (one-way ANOVA, $F=17.62, \mathrm{df}=2,12, p=0.0003$; Tukey's multiple comparison test: cochlea vs brain, $p<0.05$; kidney vs brain, $p<$ 0.05 ; cochlea vs kidney, $p>0.05$ ). The detection of stronger MMP activity in the kidney than in the brain is consistent with the observations of a previous study in rodents (Pagenstecher et al., 2000).
We then compared the MMP activity between the normal and the noise-traumatized cochleae collected at $2 \mathrm{~h}$ or $1 \mathrm{~d}$ after noise exposure. We found that the samples of the $2 \mathrm{~h}$ post-noise exposure group had a similar activity level to that in the samples of normal cochleae (Fig. $1 B$ ). In contrast, the MMP activity was reduced in the samples of the $1 \mathrm{~d}$ post-noise exposure group (Student's $t$ test, $p=0.035$; Fig. $1 C$ ). This observation suggests that acoustic trauma causes a time-dependent change in cochlear MMP activity.

\section{Exposure to intense noise causes transcriptional changes in MMPs and their related genes}

To investigate the molecular basis underlying the change in MMP enzymatic activity, we examined the transcriptional changes in the genes related to the MMP family in normal and noisetraumatized cochlear sensory epithelia.

\section{Multiple MMPs and their related genes are constitutively} expressed in the sensory epithelium of the normal cochlea Although several MMPs have been identified in the cochlea (Cho et al., 2002; Setz et al., 2011), a comprehensive analysis of the expression patterns of MMPs and their related genes is still lacking. Therefore, we began our current investigation by profiling the transcriptional expression of these genes in the normal cochlear sensory epithelium.

We first used RNA-seq to screen the mRNA transcripts in the cochlear sensory epithelium. Three biological repetitions were performed, and the transcript levels were quantified in RPKM. Using an RPKM value of $>0.1$ as the threshold, we detected the expression of 12 MMP genes, 4 TIMP genes, 9 ADAM genes, and 10 ADAMTS genes in the cochlear sensory epithelium (Table 1).

To further assess the expression pattern, we used a qRT-PCR array to measure the transcriptional expression levels of $13 \mathrm{MMP}$ genes, as well as seven associated genes (three TIMPs and four ADAMTSs) in the cochlear sensory epithelium (Table 2). Using a raw $\mathrm{Ct}$ value $<35$ as the cutoff value, we detected the expression of 12 MMPs (Mmpla, Mmp2, Mmp3, and Mmp8-16), three TIMPs (Timp1-Timp3) and four ADAMTSs (Adamts1, Adamts2, Adamts5, and Adamts8) in the cochlear sensory epithelium. To assess their relative expression levels, we normalized the expression levels to those of four reference genes (Rplp1, Hprt1, Rpl13a, and $A c t b$ ) and ranked the $\Delta C t$ values (Table 2). We identified the highly expressed genes, including Timp3, Timp2, Mmp11 and Adamts1. In contrast, the expression levels of Mmpla, Mmp3, Mmp10, and Adamts8 were low. The expression of Mmp7 was undetectable. The remaining genes were expressed at levels between those of Adamts1 and Mmp10. 
Table 1. RNA-seq analysis of expression levels of MMPs and their related genes in the normal cochlear sensory epithelium

\begin{tabular}{|c|c|c|c|}
\hline \multirow[b]{2}{*}{ Rank } & \multirow[b]{2}{*}{ Symbol } & \multicolumn{2}{|c|}{ Expression levels (RPKM) } \\
\hline & & Mean & SD \\
\hline 1 & Timp3 & 313.014667 & 48.083363 \\
\hline 2 & Timp4 & 33.766000 & 6.280977 \\
\hline 3 & Mmp2 & 21.655000 & 1.698958 \\
\hline 4 & Timp2 & 20.637100 & 0.918567 \\
\hline 5 & Mmp11 & 16.040733 & 1.412411 \\
\hline 6 & Adam 17 & 14.830200 & 1.272556 \\
\hline 7 & Adam9 & 14.389133 & 1.260569 \\
\hline 8 & Timp1 & 12.930200 & 1.310796 \\
\hline 9 & Mmp14 & 6.819683 & 1.391921 \\
\hline 10 & Adam15 & 5.001737 & 1.265057 \\
\hline 11 & Adamts5 & 3.112443 & 0.461971 \\
\hline 12 & Adamts4 & 2.985333 & 0.804253 \\
\hline 13 & Adamts1 & 2.280083 & 0.228785 \\
\hline 14 & Mmp23 & 2.136813 & 0.063010 \\
\hline 15 & Mmp15 & 2.060170 & 0.410033 \\
\hline 16 & Adam1a & 1.687500 & 0.274603 \\
\hline 17 & Mmp19 & 1.532320 & 0.375401 \\
\hline 18 & Mmp28 & 1.296060 & 0.241776 \\
\hline 19 & Adamts2 & 1.052326 & 0.222532 \\
\hline 20 & Mmp16 & 0.820286 & 0.022521 \\
\hline 21 & Adamts7 & 0.724191 & 0.095022 \\
\hline 22 & Adam19 & 0.585268 & 0.073859 \\
\hline 23 & Adam 23 & 0.533078 & 0.321016 \\
\hline 24 & Adam4 & 0.298481 & 0.162119 \\
\hline 25 & Mmp13 & 0.273117 & 0.345497 \\
\hline 26 & Adam11 & 0.263625 & 0.098319 \\
\hline 27 & Adam4/1 & 0.235758 & 0.055396 \\
\hline 28 & Mmp8 & 0.232153 & 0.075457 \\
\hline 29 & Adamts 12 & 0.228282 & 0.053822 \\
\hline 30 & Adamts 14 & 0.220333 & 0.030222 \\
\hline 31 & Adamts9 & 0.214563 & 0.080957 \\
\hline 32 & Mmp3 & 0.191781 & 0.108299 \\
\hline 33 & Adamts 15 & 0.128454 & 0.065314 \\
\hline 34 & Adamts3 & 0.116649 & 0.037044 \\
\hline 35 & Mmp12 & 0.102173 & 0.091785 \\
\hline
\end{tabular}

Data were obtained from three biological reparations and are ranked in the order of abundance from highest to lowest.

Table 2. Expression levels of MMP-related genes in the normal cochlear sensory epithelium ( $\Delta \mathrm{Ct}$ values for the reference genes)

\begin{tabular}{lcc}
\hline Gene & $\begin{array}{l}\text { Apical samples } \Delta(\mathrm{t} \\
\text { (mean } \pm \text { SD) }\end{array}$ & $\begin{array}{c}\text { Basal samples } \Delta \mathrm{Ct} \\
\text { (mean } \pm \text { SD) }\end{array}$ \\
\hline Timp3 & $0.8 \pm 0.4$ & $0.2 \pm 0.3$ \\
Timp2 & $3.6 \pm 1.5$ & $5.8 \pm 0.3$ \\
Mmp11 & $3.7 \pm 0.3$ & $5.2 \pm 0.1$ \\
Adamts1 & $4.5 \pm 0.4$ & $4.2 \pm 0.5$ \\
Mmp2 & $5.7 \pm 1.0$ & $8.4 \pm 0.1$ \\
Mmp14 & $5.8 \pm 1.5$ & $9.8 \pm 0.4$ \\
Mmp15 & $6.6 \pm 1.9$ & $10.0 \pm 0.5$ \\
Mmp16 & $6.8 \pm 0.4$ & $8.6 \pm 0.4$ \\
Timp1 & $7.2 \pm 1.4$ & $10.2 \pm 0.4$ \\
Adamts2 & $7.3 \pm 1.8$ & $12.5 \pm 0.7$ \\
Adamts5 & $7.6 \pm 1.6$ & $11.6 \pm 0.8$ \\
Mmp13 & $10.0 \pm 1.6$ & $16.0 \pm 2.5$ \\
Mmp12 & $10.5 \pm 2.9$ & $11.3 \pm 1.5$ \\
Mmp9 & $11.2 \pm 2.2$ & $16.2 \pm 0.4$ \\
Mmp10 & $13.1 \pm 0.3$ & $16.7 \pm 1.0$ \\
Mmp8 & $13.3 \pm 5.1$ & $15.1 \pm 1.5$ \\
Adamts8 & $13.6 \pm 1.7$ & $16.4 \pm 0.4$ \\
Mmp1a & $15.2 \pm 1.2$ & $16.6 \pm 0.6$ \\
Mmp3 & $15.4 \pm 2.5$ & $16.8 \pm 1.1$ \\
Mmp7 & Undetectable & Undetectable \\
\hline
\end{tabular}

Data are means \pm SD from four biological repeats, and are ranked in the order of abundance from highest to lowest.
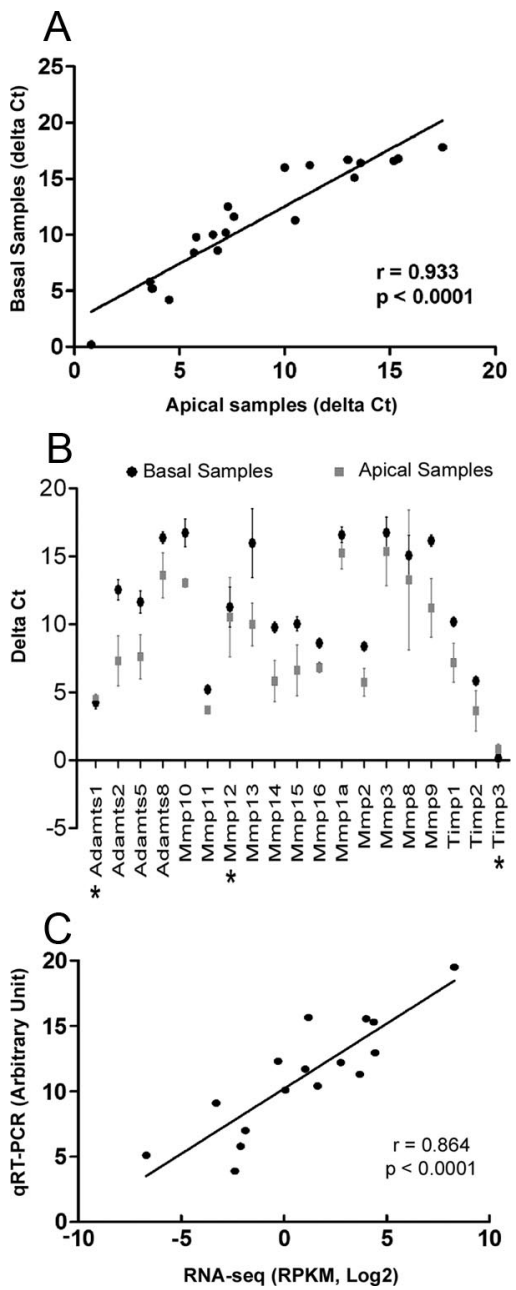

Figure 2. Comparison of the expression pattern of MMP-related genes between the apical and basal regions of the cochlear sensory epithelium. $\boldsymbol{A}$, Scatter plot showing the correlation between the expression levels $(\Delta C t)$ of MMPs and their related genes in apical samples compared with those in basal samples (analyzed with Pearson's analysis). $\boldsymbol{B}$, Comparison of the expression levels of MMPs and their related genes between the apical and the basal samples. Most of the examined genes exhibited higher $(t$ values (lower expression levels) in the basal samples (fold difference $>2$ and FDR $=0$, SAM analysis), except for three genes (marked with asterisks) that showed either a small C $\mathrm{t}$ difference $(<2$, Mmp 12) or lower Ct values in the basal samples (Adamts 1 and Timp3). However, these differences for Adamts 1 and Timp3 were relatively minor ( $\Delta C \mathrm{C}$ difference $<0.5$ ). C, Correlation between the RNA-seq and qRT-PCR data for the genes identified with both assays (analyzed with Pearson's analysis).

The apical and basal regions of the cochlear sensory epithelium are known to have different susceptibilities to acoustic trauma (Thorne et al., 1984; Bohne et al., 1987; Hu et al., 2002; Pouyatos et al., 2009). We sought to determine whether the expression patterns of MMPs and their related genes differed in these two regions. We found that none of the genes tested was expressed exclusively in one region and that the expression levels between the two regions were highly correlated (Fig. 2A). However, a majority of the examined genes had higher expression levels in the apical samples than in the basal samples (SAM analysis, delta set at 0.96 , generating an FDR $<1.3 \%$; Fig. $2 B$ ). Only two genes (Adamts1 and Timp3) exhibited higher expression levels in the basal sample, although the differences were relatively small $(\Delta \mathrm{Ct}$ difference $<0.5)$. This result indicates that the expression levels of MMPs and their related genes differ in the apical and basal partitions of the cochlear sensory epithelium relative to the expression levels of reference genes. 
Using the Pearson's analysis, we examined the correlation between the expression levels evaluated by the RNA-seq analysis and those evaluated by the qRT-PCR array analysis and found a highly correlated expression pattern (Fig. $2 C, r=0.864, p<$ $0.0001)$. Together, our expression analyses identify a group of MMPs and their related genes that are constitutively expressed in the cochlear sensory epithelium under normal physiological conditions. Importantly, many of these genes had not been identified previously in the cochlea.

Exposure to intense noise causes site-and time-dependent changes in the expression levels of MMP-related genes

To determine the expression changes in MMPs and their related genes after acoustic trauma, we examined the MMP expression at $2 \mathrm{~h}, 1 \mathrm{~d}$, and $28 \mathrm{~d}$ after noise exposure using the qRT-PCR array. The first two time points represent the acute phases of cochlear pathogenesis, and the last time point represents the stable phase of cochlear pathology. Again, we divided the cochlear sensory epithelium into the apical and basal samples to investigate the site-specific changes.

At $2 \mathrm{~h}$ after noise exposure, five genes in the apical portion of the organ of Corti were upregulated (Adamts1, Mmp7, Mmp3, Timp1, and Timp3; SAM analysis, FDR =0; Table 3). Among these, two are MMP family members (Mmp3 and Mmp7), one is a member of the ADAMTS family (Adamts1), and two are inhibitors of MMPs (Timp1 and Timp3). None of the genes tested were downregulated in the apical samples at the $2 \mathrm{~h}$ time point.

Seven genes in the basal portion of the organ of Corti were upregulated $2 \mathrm{~h}$ after noise exposure (Mmp3, Mmp7, Mmp13 Mmp14, Adamts1, Adamts8, and Timp1), and one gene (Mmp11) was downregulated (SAM analysis, FDR =0; Table 2). Among the genes upregulated in the basal portion of the sensory epithelium, four genes (Mmp7, Mmp3, Timp1, and Adamts1) were also altered in the apical tissues (Fig. 3). All of the genes that covaried were upregulated with greater fold changes in the basal samples than the apical samples. Four genes (Mmp13, Mmp14, Mmp11, and Admts8) with expression changes were found exclusively in the basal samples, and only one (Timp3) was found exclusively in the apical samples. Overall, acoustic overstimulation induced changes in the expression of a greater number of genes in the basal section of the cochlear sensory epithelium during the acute phase of cochlear pathogenesis.

To determine whether the changes in the expression levels of the MMP-related genes persisted in the later parts of the acute phase and in the recovery phases of cochlear pathogenesis, we profiled the expression patterns at $1 \mathrm{~d}$ and $28 \mathrm{~d}$ after noise exposure. These time points were analyzed using only the samples obtained from the apical sections of the sensory epithelia. We excluded the basal samples at these time points because of the concern that accumulated cell death in this region could pose difficulties in the interpretation of the results.

At $1 \mathrm{~d}$ after exposure, all upregulated gene expression that was observed at $2 \mathrm{~h}$ after exposure returned to the pre-noise levels except for one gene, Timp1, which remained upregulated (16.3-
Table 3. Fold changes in MMP-related genes $2 \mathrm{~h}$ after noise exposure relative to preexposure levels

\begin{tabular}{|c|c|c|c|c|}
\hline \multirow[b]{2}{*}{ Gene } & \multicolumn{2}{|c|}{ Apical partition } & \multicolumn{2}{|c|}{ Basal partition } \\
\hline & Fold change & $q$ value (\%) & Fold change & $q$ value (\%) \\
\hline \multicolumn{5}{|l|}{ Upregulation } \\
\hline Adamts1 & 8.5 & 0.00 & 11.2 & 0.00 \\
\hline Mmp7 & 49.9 & 0.00 & 289.9 & 0.00 \\
\hline Timp1 & 8.1 & 0.00 & 82.4 & 0.00 \\
\hline Mmp3 & 22.6 & 0.00 & 104.5 & 0.00 \\
\hline Тimp3 & 2.1 & 0.00 & & \\
\hline Adamts8 & & & 5.3 & 0.00 \\
\hline Mmp13 & & & 20.4 & 0.00 \\
\hline Mmp14 & & & 2.3 & 0.00 \\
\hline \multicolumn{5}{|c|}{ Downregulation } \\
\hline Mmp11 & & & 4.96 & 0.00 \\
\hline
\end{tabular}

Data were obtained from four biological repeats.
Expressed in the apical

Expressed in the basal xposure. The image lists the genes for which the expression levels were exclusively or concurrently altered in the apical and basal sections of the sensory epithelium. All of the listed genes were upregulated except for Mmp 11 (marked by the asterisk), which was xpressed in both the apical and basal sections

fold difference compared with the pre-noise level). More noticeably, 13 genes showed a trend of downregulation (SAM analysis, FDR $=6.2 \%$; Table 4 ). The data from both the $2 \mathrm{~h}$ and $1 \mathrm{~d}$ time points suggested that the acute-phase pathology was characterized by a dynamic change in gene regulation.

By $28 \mathrm{~d}$ after exposure, four genes (Mmp7, Mmp1, Mmp10, and Mmp3) were upregulated (Table 4). Among these upregulated genes, $M m p 7$ and $M m p 3$ exhibited a significant upregulation at $2 \mathrm{~h}$ after noise exposure, suggesting the presence of a second wave of upregulation of these genes. Noticeably, the major change at this time point was the downregulation of the gene expression (Table 4). Together, these observations suggest that the modulation of the expression of MMPs and their related genes is a time-dependent event (Fig. 4), consistent with the observations of previous investigations on traumatic brain injury (Kolar et al., 2008).

\section{Expression changes in Timp1 and Timp2 after acoustic trauma}

MMP activity is regulated in part by endogenous inhibitors, including TIMPs. To determine whether acoustic trauma causes 
Table 4. Fold changes in MMP-related genes $1 \mathrm{~d}$ and $28 \mathrm{~d}$ after noise exposure in the apical sensory epithelium

\begin{tabular}{|c|c|c|c|c|}
\hline \multirow[b]{2}{*}{ Gene } & \multicolumn{2}{|c|}{$1 \mathrm{~d}$ after noise exposure } & \multicolumn{2}{|c|}{$28 \mathrm{~d}$ after noise exposure } \\
\hline & Fold change & $q$ value (\%) & Fold change & $q$ value $(\%)$ \\
\hline \multicolumn{5}{|l|}{ Upregulation } \\
\hline Timp1 & 16.3 & 0.00 & & \\
\hline Mmp1a & & & 7.2 & 0.00 \\
\hline Mmp3 & & & 3.2 & 2.72 \\
\hline Mmp7 & & & 12.7 & 0.00 \\
\hline Mmp10 & & & 3.7 & 1.43 \\
\hline \multicolumn{5}{|c|}{ Downregulation } \\
\hline Adamts2 & 6.9 & 6.19 & 16.6 & 0.00 \\
\hline Mmp14 & 3.4 & 6.19 & 10.0 & 0.00 \\
\hline Mmp15 & 5.2 & 6.19 & 9.9 & 0.00 \\
\hline Timp2 & 3.7 & 6.19 & 7.1 & 0.00 \\
\hline Mmp1a & 4.1 & 6.19 & & \\
\hline Mmp9 & 5.2 & 6.19 & & \\
\hline Adamts1 & & & 3.7 & 0.00 \\
\hline Adamts5 & & & 8.5 & 0.00 \\
\hline Mmp2 & & & 10.9 & 0.00 \\
\hline Mmp11 & & & 4.5 & 0.00 \\
\hline Mmp16 & & & 2.9 & 0.00 \\
\hline
\end{tabular}

Data for $1 \mathrm{~d}$ after noise exposure were obtained from four biological repeats, and the data for $28 \mathrm{~d}$ after noise exposure were obtained from three biological repeats.

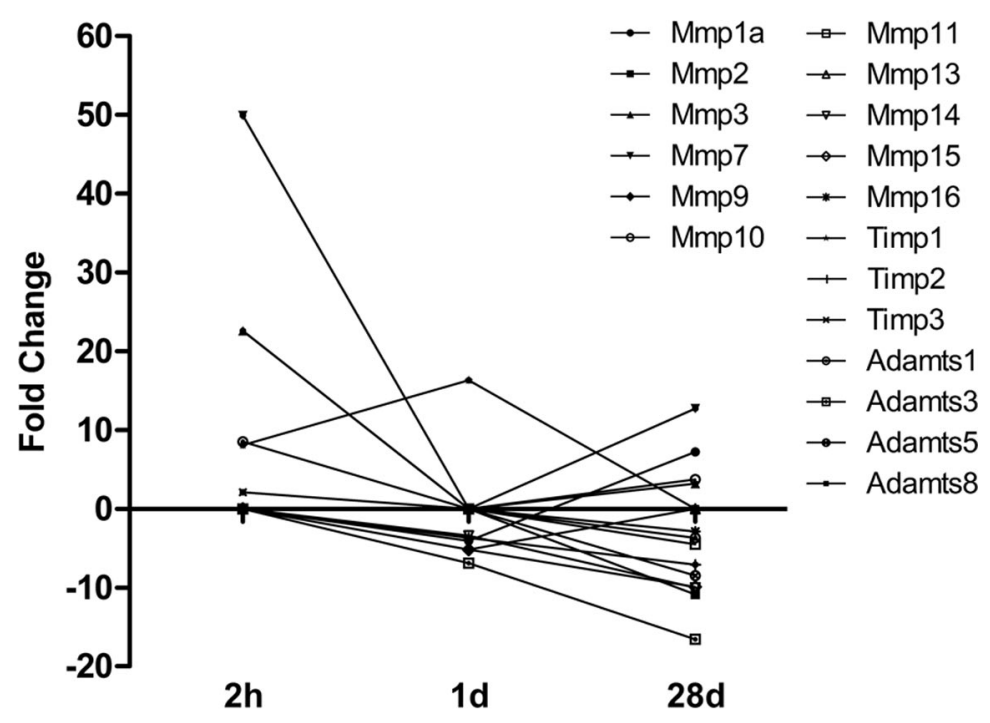

Figure 4. Dynamic changes in the expression levels of the MMP-related genes at three time points ( $2 \mathrm{~h}, 1 \mathrm{~d}$, and $28 \mathrm{~d}$ ) after noise exposure. To reduce the complexity of the figure, the data presented are the expression changes with FDR values $<6.19 \%$ (SAM analysis). For the expression changes with greater FDRs, the expression values are assigned to zero.

changes in TIMP expression, we examined the changes in the protein expression of two TIMPs (Timp1 and Timp2) at $2 \mathrm{~h}$ after noise exposure. Timp1 was selected for analysis because it was upregulated at the mRNA level in both the apical and basal partitions of the sensory epithelium at $2 \mathrm{~h}$ after noise exposure (Table 3). Timp2 was selected because it was highly expressed in the normal cochlea (Table 2) and was downregulated at both $1 \mathrm{~d}$ and $28 \mathrm{~d}$ after noise exposure. An immunolabeling assay was used to assess the spatial distribution of the changes in the organ of Corti.

In the normal cochlea, Timp1 immunoreactivity was weakly present in the cytoplasm of the sensory cells and the supporting cells (Fig. 5B, see $A$ for the nuclear morphology of the cells in the same area). In noise-traumatized cochleae, we observed a cellstate-dependent change in Timp1 immunoreactivity. To define the progression of sensory cell degeneration, we used nuclear morphology as a marker because this phenotype of sensory cell degeneration is an early event of cell damage that progresses in a step-by-step manner (Yang et al., 2004; Hu et al., 2006). Compared with the staining intensity of Timp1 in sensory cells with normal nuclear morphology, sensory cells that had slight nuclear condensation (an increase in propidium iodide fluorescence but a decrease in the nuclear size) exhibited reduced Timp1 immunoreactivity (Fig. $5 D-F$ ). In contrast, Timp1 immunoreactivity was increased in sensory cells with advanced nuclear condensation as evidenced by the appearance of small nuclear fragments (Fig. 5G-I). Noticeably, not all cells with advanced nuclear condensation exhibited increased Timp 1 immunoreactivity, suggesting that the increase in Timp1 immunoreactivity is a transient event of cell degeneration or that different cells undergo different molecular changes. We quantified the number of sensory cells that exhibited nuclear malformation and the numbers of cells that showed increased Timp1 immunoreactivity and found the ratio to be $\sim 3: 1$ (Fig. 5C). Because only a few sensory cells exhibited the early signs of nuclear condensation, we did not quantify their number. Together, this observation suggests the presence of a biphasic expression change in the Timp1 protein with an early downregulation and a subsequent upregulation during sensory cell degeneration.

Timp2 immunoreactivity was only weakly present in the sensory cells of the normal sensory epithelium (Fig. 6A-C). After acoustic trauma, an increase in Timp2 immunoreactivity was found in the circumferential ring of outer hair cells, in which the cells form junctions with Deiters cells (Fig. 6E). The double labeling of the tissue with propidium iodide revealed that all of the cells with increased immunoreactivity in the circumferential rings exhibited malformed nuclei (Fig. $6 D-F)$. Again, not all sensory cells with nuclear condensation exhibited increased Timp2 immunoreactivity. The quantitative analysis of the number of sensory cells with nuclear malformation and the number of cells with increased Timp2 immunoreactivity revealed a ratio of 3.5:1 (Fig. $6 G)$, similar to the ratio observed for Timp1 staining.

Nuclear condensation and fragmentation are morphological signs of apoptosis. To confirm that the cells with these nuclear changes were dying by apoptosis, we stained the tissues with an antibody against Bax, a proapoptotic protein (Lalier et al., 2007). We found that all of the cells showing condensed or fragmented nuclei displayed strongly increased Bax immunoreactivity (Fig. 6H,I). This observation is consistent with our previous observations using other apoptosis markers (the activation of caspase- 3 and the terminal deoxynucleotidyl transferase-mediated dUTP-digoxigenin nick end labeling) in sensory cells showing nuclear condensation (Hu et al., 2009; Cai et al., 2012). Together, the observations suggest that Timp1 and Timp2 are involved in the apoptotic process in noise-induced cochlear damage.

To verify the specificity of the antibodies used in the current investigation, we confirmed the molecular weights of the proteins targeted by the Timp1, Timp2, and Bax antibodies using a Western blotting assay. We detected a clear $24 \mathrm{kDa}$ band for Timp2 and a $21 \mathrm{kDa}$ band for Bax, consistent with the molecular weights 

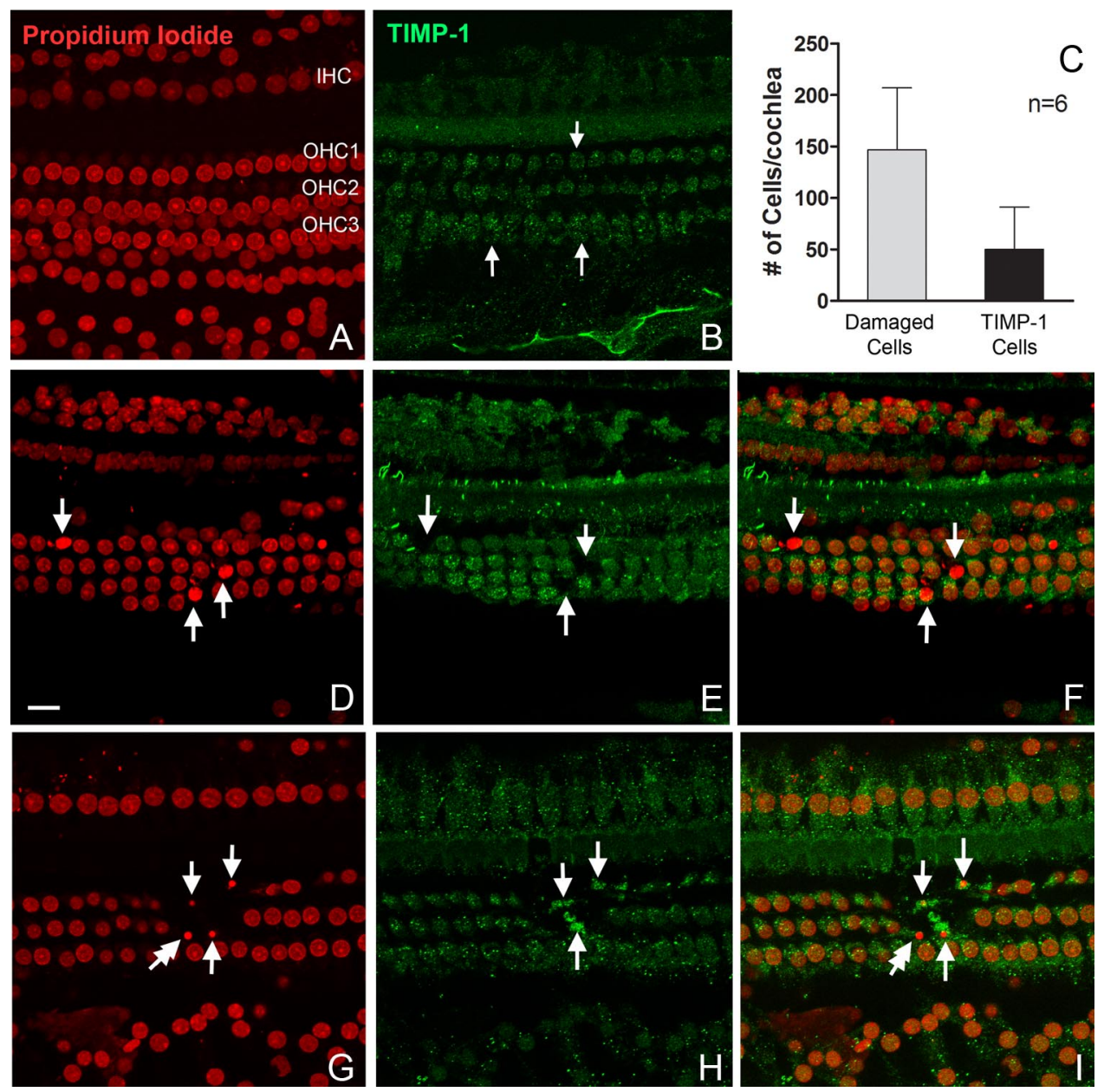

Figure 5. Expression changes in the Timp1 protein in the sensory epithelium at $2 \mathrm{~h}$ after noise exposure. $\boldsymbol{A}, \boldsymbol{B}$, The Timp1 immunoreactivity in a normal organ of Corti. The tissue was doubly stained with propidium iodide (red fluorescence, $\boldsymbol{A}$ ) for the illustration of the nuclei and an antibody against Timp1 (green fluorescence, $\boldsymbol{B}$ ). The TIMP1 immunoreactivity was present primarily in the cytoplasm (arrows). IHC, Inner hair cell; $\mathrm{OHC1}, \mathrm{OHC}, \mathrm{OHC}$, first, second, and third rows of outer hair cells, respectively. $\boldsymbol{D}-\boldsymbol{F}$, Timp1 immunolabeling in a sensory epithelium collected at $2 \mathrm{~h}$ after the noise exposure. $\boldsymbol{D}$ shows the nuclear morphology. $\boldsymbol{E}$ shows the Timp1 immunoreactivity. $\boldsymbol{F}$ is a superimposed image of $\boldsymbol{D}$ and $\boldsymbol{E}$. The arrows in $\boldsymbol{D}$ point to the outer hair cells that exhibited nuclear condensation. The immunoreactivity of Timp 1 in these cells was decreased (arrows in $\boldsymbol{E}$ and $\boldsymbol{F}$ ). $\mathbf{G}-\boldsymbol{I}$, Timp1 immunoreactivity in sensory cells showing advanced nuclear condensation. The arrows in $\boldsymbol{G}$ point to the outer hair cells that exhibited fragmented nuclei. TIMP1 immunoreactivity in these cells was increased (arrows in $\boldsymbol{H}$ ) compared with the neighboring outer hair cells that had relatively normal nuclear morphology. The double arrow in $\mathbf{G}-\mathbf{I}$ points to a cell with a fragmented nucleus but without increased Timp 1 immunoreactivity. $\boldsymbol{C}$, The average number of sensory cells that exhibited nuclear malformation and the average of number of sensory cells that exhibited increased Timp1 immunoreactivity (mean \pm SD). Sample size, $n$ indicates the number of cochleae. Scale bar: $\mathbf{D}, 20 \mu \mathrm{m}$.

of these two proteins. In the cochlear tissue, we did not identify the Timp1 band, possibly because of insufficient protein level for the Western blotting assay. We therefore used HEK293 cell lysate (sc-110547; Santa Cruz Biotechnology) for Timp1-positive control and found a strong $30 \mathrm{kDa}$ band, which is consistent with the molecular weight of this protein. In addition to Western blotting for primary antibody assessment, we examined the nonspecific staining of the secondary antibodies by omitting the primary antibody and detected no clear fluorescence in the tissues.

\section{MMP inhibition compromises cochlear function}

Given the current finding that acoustic overstimulation altered MMP activity, we sought to determine whether the change in MMP activity affected cochlear function. To this end, we inhibited MMP activity with doxycycline, a broad-spectrum inhibitor of MMPs that has been used in both clinical and basic research for the inhibition of MMP activity (Clark et al., 1997; Hanemaaijer et al., 1998; Lee et al., 2001; Shlopov et al., 2001; Bedi et al., 2010). We used a dose of $50 \mathrm{mg} \cdot \mathrm{kg}^{-1} \cdot \mathrm{d}^{-1}$ for $7 \mathrm{~d}$, a treatment para- digm that has been shown to be effective for MMP inhibition in rats (Curci et al., 1998; Nogueira et al., 2011).

The ABR thresholds were measured before and after the treatment. A two-way ANOVA (frequency $\times$ time) revealed a significant time effect $(F=34$, df $=2,110, p<0.0001$; Fig. 7A). Compared with the pretreatment thresholds, the average threshold shifts were $15.0 \pm 18.9$ to $25.8 \pm 21.3 \mathrm{~dB}$ (mean $\pm \mathrm{SD}$ ) at the time of the completion of the doxycycline treatment (Bonferroni's post hoc test, $p<0.05-0.001$, depending on testing frequency). These threshold shifts partially recovered $7 \mathrm{~d}$ after the completion of the drug treatment, resulting in reduced threshold shifts ranging from $7.5 \pm 21.8$ to $17.1 \pm 19.9 \mathrm{~dB}$ (mean $\pm \mathrm{SD}$ ). At this time point, the threshold shifts were significant at only two tested frequencies ( 5 and $10 \mathrm{kHz}$, Bonferroni's post hoc test, $p<$ $0.05)$. The control animals, which received a saline treatment with an identical application paradigm, exhibited no significant threshold shifts at the time of the completion of the treatment $(F=3.76, \mathrm{df}=1,45, p>0.05$; Fig. $7 B)$. Together, these results 

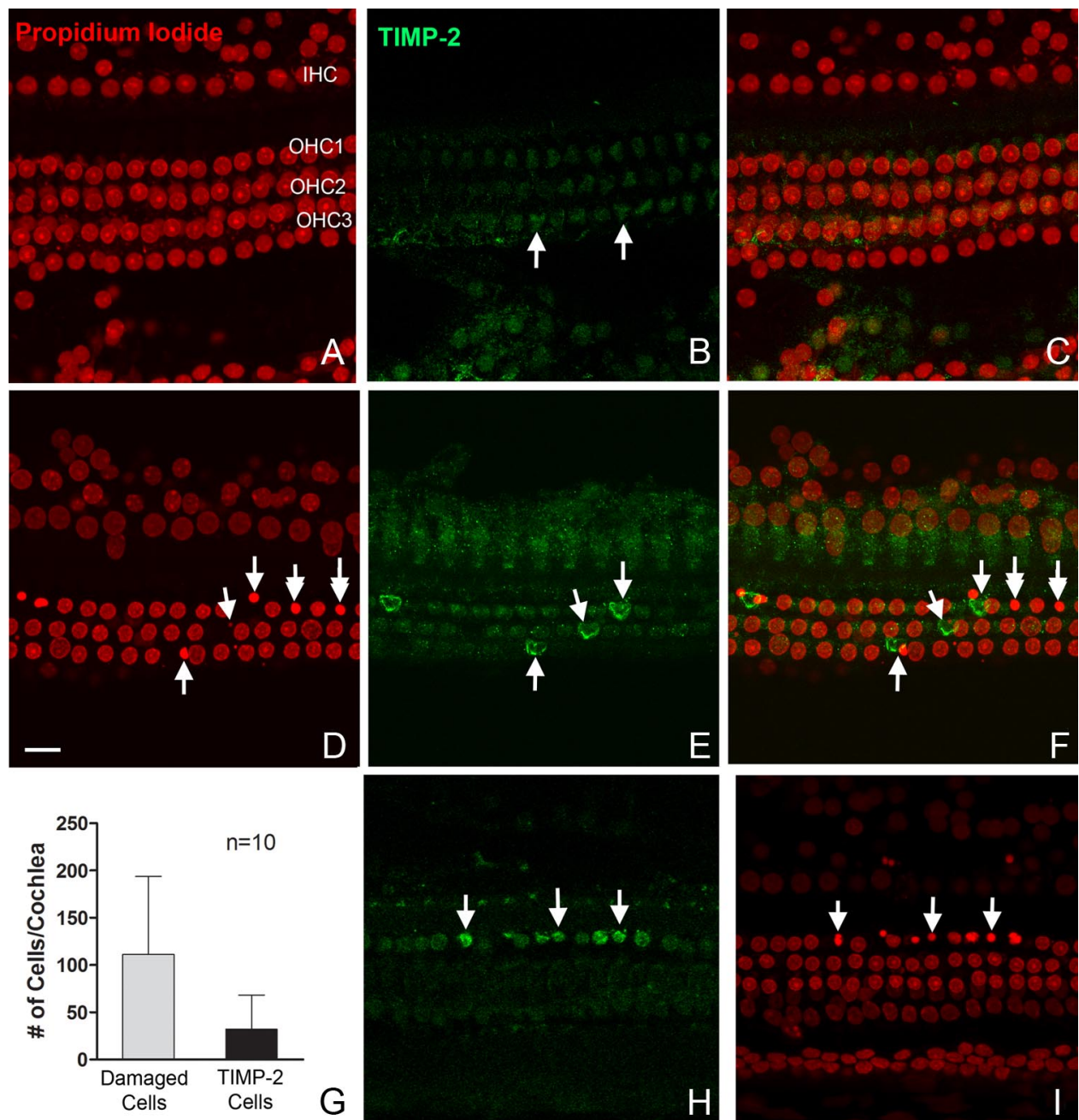

Figure 6. Expression changes in the Timp2 protein in the cochlear sensory epithelium after acoustic trauma. $\boldsymbol{A}, \boldsymbol{B}$, Timp2 immunoreactivity in a normal sensory epithelium doubly stained with propidium iodide (red fluorescence in $\boldsymbol{A}$ ) for the illustration of nuclei and an antibody against Timp2 (green fluorescence in $\boldsymbol{B}$ ). $\boldsymbol{C}, \boldsymbol{A}$ combined image from $\boldsymbol{A}$ and $\boldsymbol{B}$. The Timp2 immunoreactivity was weakly present in the cytoplasm. IHC, Inner hair cell; $\mathrm{OHC1}, \mathrm{OHC2}, \mathrm{OHC}$, first, second, and third rows of outer hair cells, respectively. $\mathbf{D}-\boldsymbol{F}$, TIMP2 immunolabeling in a sensory epithelium collected at $2 \mathrm{~h}$ after the noise exposure. The arrows in $\boldsymbol{D}$ point to the outer hair cells with condensed nuclei. These cells exhibited a marked increase in Timp 2 immunoreactivity in the circumferential ring of the outer hair cells (arrows in $\boldsymbol{E}$ and $\boldsymbol{F}$ ). The double arrows point to the cells that exhibited nuclear condensation but not increased Timp 2 immunoreactivity in the circumferential ring. There was no increased immunoreactivity in the circumferential rings of the sensory cells that had normal nuclear morphology. $\mathbf{G}$, The average number of the sensory cells per cochlea that exhibited nuclear malformation and the average number of sensory cells that exhibited increased Timp 1 immunoreactivity. $\boldsymbol{H}, \boldsymbol{I}$, Bax immunoreactivity in a noise-traumatized organ of Corti. The arrows in $\boldsymbol{H}$ point to the sensory cells with increased Bax immunoreactivity. Note that these cells also displayed nuclear condensation. Only weak Bax immunoreactivity was observed in the sensory cells with normal nuclear morphology. Scale bar: D, $20 \mu \mathrm{m}$.
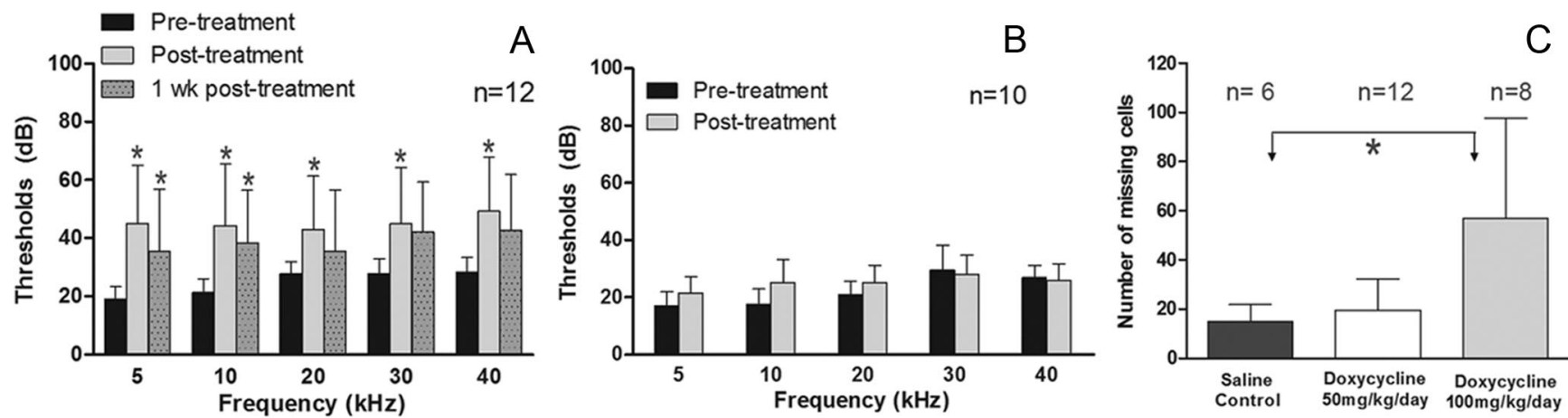

Figure 7. Effect of the doxycycline treatment and the saline treatment on the ABR thresholds and the cochlear sensory cell viability. $A$, Comparison of the ABR thresholds measured before, immediately after, and 1 week after the doxycycline treatment $\left(50 \mathrm{mg} \cdot \mathrm{kg}^{-1} \cdot \mathrm{d}^{-1}\right.$ for $7 \mathrm{~d}$ ) across the five tested frequencies. The asterisks indicate the presence of significant differences compared with the pretreatment thresholds (two-way ANOVA, Bonferroni's post hoc test, $p<0.05-0.001$ ). B, Comparison of the ABR thresholds tested before and after the saline treatment in the control group animals. No significant differences were present. $C$, Comparison of the numbers of missing sensory cells per cochlea among the normal animals (saline treated), the animals that received a dose of $50 \mathrm{mg} \cdot \mathrm{kg}^{-1} \cdot \mathrm{d}^{-1}$ doxycycline treatment for $7 \mathrm{~d}$, and the animals that received a dose of $100 \mathrm{mg} \cdot \mathrm{kg}^{-1} \cdot \mathrm{d}^{-1}$ for $7 \mathrm{~d}$. The asterisk indicates a significant difference (one-way ANOVA, Tukey's test, $\left.{ }^{*} p<0.05\right)$. The error bars represent the SD. $n$ indicates the number of cochleae. 
indicate that the inhibition of MMP activity compromises cochlear function.

Many ototoxic agents affect cochlear function by affecting sensory cell viability. To determine whether doxycycline treatment at the current dosage compromised sensory cell viability, we examined nuclear morphology, an indicator of cell damage, $14 \mathrm{~d}$ after doxycycline treatment. Compared with the normal control cochleae that received only a saline treatment, the doxycycline-treated ears exhibited no significant increase in the number of missing cells (Fig. 7C, one-way ANOVA, Kruskal-Wallis test, $p>0.05)$. This result indicates that, at the currently used dosage, the doxycycline treatment did not cause significant sensory cell death. Because MMP inhibition has been shown to cause sensory cell death in cultured cochlear sensory tissues (Setz et al., 2011), we wanted to determine whether the lack of cell death after the doxycycline treatment was attributable to a dosage that was insufficient to induce cell death. We therefore increased the dose from 50 to $100 \mathrm{mg} \cdot \mathrm{kg}^{-1} \cdot \mathrm{d}^{-1}$ for $7 \mathrm{~d}$. With this high-dose treatment, we observed a significant difference in the numbers of missing cells between the treated and the control ears (one-way ANOVA, Kruskal-Wallis test, $p<0.05$ ), indicating that a high dose of doxycycline is able to compromise cell viability.

To confirm that the doxycycline treatment inhibited MMP activity, we examined the cochlear MMP activity immediately after the completion of the doxycycline treatment (50 $\mathrm{mg} \cdot \mathrm{kg}^{-1} \cdot \mathrm{d}^{-1}$ for $7 \mathrm{~d}$ ). We observed a decrease in MMP activity compared with the saline-treated control ears (Fig. 8A), although the difference was not statistically significant (Student's $t$ test, $p=$ 0.13 ) because of large individual variability. We also examined the mRNA expression levels of four MMP genes ( $M m p 9$, Mmp11, $M m p 13$, and Mmp14) to determine whether the doxycycline treatment would affect MMP transcription. We selected these MMP mRNAs for analysis because their expression or activity has been found to be inhibited by doxycycline treatment (Greenwald et al., 1998; Hanemaaijer et al., 1998; Shlopov et al., 2001; Lee et al., 2004). We observed no significant changes in the expression levels of these genes after the doxycycline treatment (Student's $t$ test, $p>0.05$; Fig. $8 B$ ).

MMP inhibition alters cochlear responses to acoustic trauma We proceeded to investigate whether the inhibition of MMP activity affects the cochlear responses to acoustic overstimulation ( $120 \mathrm{~dB}$ SPL for $2 \mathrm{~h}$ ) by examining the effect of a $7 \mathrm{~d}$ application of doxycycline treatment $\left(50 \mathrm{mg} \cdot \mathrm{kg}^{-1} \cdot \mathrm{d}^{-1}\right)$. The drug was administered $1 \mathrm{~d}$ before noise exposure, and the same daily dosage was maintained for $6 \mathrm{~d}$ after the noise exposure. This time period covers the acute phases and the beginning of the chronic phases of cochlear pathogenesis.

We first examined the effect of the drug effect during the treatment period. The ABRs were measured before, during, and immediately after the completion of the drug treatment. To simplify the analysis, we averaged the thresholds tested at different frequencies for each animal and conducted a two-way ANOVA (time $\times$ treatment) to examine the time-dependent changes in the ABR thresholds. We observed a time-dependent difference in the ABR thresholds between the doxycycline-treated and salinetreated groups $(F=3.84, \mathrm{df}=2,154, p<0.05$; Fig. $9 A)$. There was no significant threshold difference between the two groups before doxycycline treatment (Tukey's test, $p>0.05$ ). There was also no significant difference after three doses of the doxycycline treatment (just before the noise exposure; Tukey's test, $p>0.05$ ), suggesting that the doxycycline-treated and the control groups had similar hearing sensitivities at the time of noise exposure. At $2 \mathrm{~h}$ after noise exposure, the doxycycline-treated animals exhibited a slightly greater hearing loss than the saline-treated animals, but the difference was not statistically significant ( $4.3 \mathrm{~dB}$; Tukey's test, $p>0.05)$. By the end of the $7 \mathrm{~d}$ doxycycline treatment, the animals exhibited a greater threshold shift than the saline-treated animals $(8.8 \mathrm{~dB}$; Tukey's test, $p<0.01)$. The difference appeared relatively homogenous across the five tested frequencies (Fig. $9 B)$. This observation suggests that the doxycycline treatment potentiates noise-induced hearing loss during the period of the drug treatment.

To determine whether the $7 \mathrm{~d}$ doxycycline treatment affected noise-induced permanent hearing loss, we repeated the hearing test at 4 weeks after the noise exposure (3 weeks after the completion of the doxycycline treatment). A two-way ANOVA (treatment $X$ frequency) revealed that the greater hearing loss in the doxycycline-treated animals observed at the end of the drug treatment was no longer present. Instead, the doxycyclinetreated animals exhibited a slightly better hearing sensitivity than the saline-treated animals, although the difference was not statistically significant (Tukey's test, $p>0.05$; Fig. 9C).

Although doxycycline has been widely used as a broadspectrum MMP inhibitor, this drug has other cellular effects, including anti-inflammatory effects (Krakauer and Buckley, 2003). To confirm that the modulation of MMPs could alter the cochlear responses to acoustic trauma, we used an Mmp7 knockout mouse model (B6.129-Mmp $\left.7^{\mathrm{tm} 1 \mathrm{Lmm}} / \mathrm{J}\right)$ to investigate the effect of targeted deletion of $M m p 7$ on the changes in cochlear function after acoustic overstimulation. $M m p 7$ was selected for additional analysis because it had the greatest change in expression after acoustic trauma compared with the changes in expression of the other examined MMP genes.

Under normal physiological conditions, $M m p 7^{-/-}$mice and age-matched wild-type controls (C57BL/6J) exhibited similar baseline ABR thresholds (two-way ANOVA, $F=1.9$, $\mathrm{df}=1,100$, $p=0.19$; Fig. $10 A$ ), suggesting that knocking out $M m p 7$ does not affect the hearing sensitivity of the mice. However, after noise exposure, the $M m p 7^{-1-}$ mice exhibited greater hearing loss (Fig. $10 \mathrm{~B})$. A two-way ANOVA (treatment $\times$ frequency) revealed an average of $11.6 \pm 8.6 \mathrm{~dB}$ difference in the ABR thresholds be- 

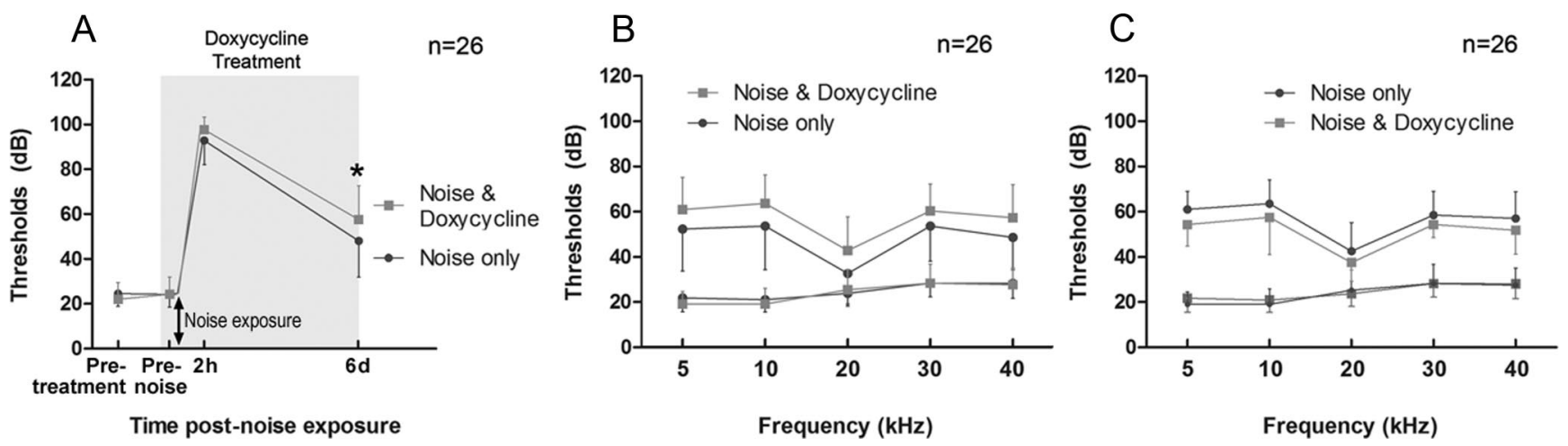

Figure 9. The effect of doxycycline treatment on noise-induced ABR changes. $A$, Comparison of the ABR thresholds between the animals treated with or without doxycycline during the $7 \mathrm{~d}$ treatment $\left(50 \mathrm{mg} \cdot \mathrm{kg}^{-1} \cdot \mathrm{d}^{-1}\right)$, marked by the shaded area. ${ }^{*} p<0.05$ (two-way ANOVA, Tukey's test). $\boldsymbol{B}$, The difference in ABR thresholds between the animals treated with or without the $7 \mathrm{~d}$ treatment of doxycycline is relatively homogenous across the five tested frequencies. C, Comparison of the ABR thresholds between the doxycycline-treated and the control animals measured 4 weeks after the noise exposure ( 3 weeks after the completion of the doxycycline treatment). There were no statistically significant differences between the thresholds across all five of the tested frequencies (two-way ANOVA, Tukey's test, $p>0.05$ ). $n$ indicates the number of cochleae.
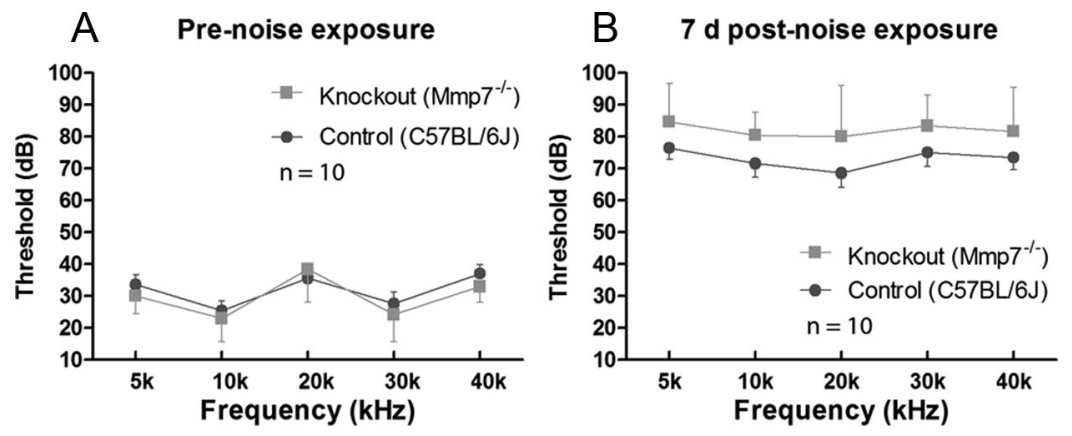

Figure 10. Comparison of the ABR thresholds between the $M m p 7^{-1-}$ and wild-type (C57BL/6J) mice. $A$, No significant difference in the ABR thresholds between the $M m p 7^{-1-}$ and wild-type mice under the normal physiological conditions. $\boldsymbol{B}$, The $\mathrm{Mmp}^{-1-}$ mice exhibit an average of $11.6 \pm 8.6 \mathrm{~dB}$ greater hearing loss than the wild-type mice $7 \mathrm{~d}$ after noise exposure (two-way ANOVA, $F=14.0, \mathrm{df}=1,100, p<0.01$ ). $n$ indicates the number of cochleae for each group.

tween the knock-out and the wild-type mice $(F=14.0, \mathrm{df}=$ $1,100, p<0.01)$. The difference is not dependent on frequency $(F=0.071, \mathrm{df}=4,100, p>0.05)$. This observation suggests that the interruption of $M m p 7$ potentiates noise-induced hearing loss. To confirm that the altered physiological response to acoustic overstimulation was attributable to a lack of Mmp7 expression, we measured the transcriptional expression levels of $M m p 7$ in the $M m p 7^{-/-}$and wild-type mice in quiet control conditions and after noise exposure. Without exposure to noise, Mmp7 transcripts were undetectable in the cochlear sensory epithelium of both the wild-type and the $M m p 7^{-1-}$ mice. After the noise exposure, the expression became detectable in the wild-type mice, whereas it remained undetectable in the $\mathrm{Mmp}^{7^{-1}}$ mice, suggesting that the knock-out mice lacked the Mmp7 response to acoustic overstimulation. Together, these observations further support the finding that the MMPs participate in the cochlear responses to acoustic trauma.

\section{Short-term application of doxycycline reduces cochlear damage after acoustic trauma}

Considering that the treatment with doxycycline for $7 \mathrm{~d}$ compromised hearing sensitivity in normal animals (Fig. 7A), we wondered whether shortening the doxycycline treatment would reduce the impact of the doxycycline treatment on acute hearing loss and enhance the hearing recovery during the late phase of cochlear pathogenesis. To address this question, we administered three doses of doxycycline $\left(50 \mathrm{mg} \cdot \mathrm{kg}^{-1} \cdot \mathrm{d}^{-1}\right)$ before the noise exposure (twice on $1 \mathrm{~d}$ before the noise exposure and once on the day of the noise exposure). Again, a two-way ANOVA revealed a time-dependent difference in the ABR thresholds between the doxycyclinetreated and the saline-treated animals $(F=4.7, \mathrm{df}=1,83, p<0.03$; Fig. 11). We observed no significant differences in the ABR thresholds between the doxycyclineand saline-treated animals after the completion of the doxycycline treatment (just before the noise exposure; Tukey's test, $p>0.05)$. At $2 \mathrm{~h}$ after the noise exposure, the doxycycline-treated animals exhibited slightly greater hearing loss than the saline-treated noisecontrol animals $(5.5 \mathrm{~dB}$; Tukey's test, $p<0.001)$. However, at 14 and $28 \mathrm{~d}$ after the noise exposure, the doxycycline-treated animals exhibited a much greater hearing recovery than the saline-treated noise control animals (9.8 and $12.9 \mathrm{~dB}$ for 14 and $28 \mathrm{~d}$ after noise exposure, respectively; Tukey's test, $p<0.001)$. This result suggests that a short-term doxycycline treatment before noise exposure reduces permanent hearing loss after the noise exposure. Together, the current results suggest that the inhibition of MMP activity by doxycycline treatment modulates the cochlear responses to acoustic overstimulation.

The reduction in permanent hearing loss with doxycycline treatment is a promising result. We wanted to determine whether the treatment could also reduce the level of sensory cell damage. To this end, we compared the differences in the numbers of missing cells between the doxycycline-noise-treated $\left(50 \mathrm{mg} \cdot \mathrm{kg}^{-1} \cdot \mathrm{d}^{-1}\right.$ for $\left.7 \mathrm{~d}\right)$ and the saline-noise-treated (Fig. 12) cochleae . The doxycyclinetreated animals exhibited, on average, a $41.0 \%$ reduction in the total number of missing cells compared with the saline-noise control animals, and the difference was statistically significant (Student's $t$ test, $p<0.01)$. To determine whether the differences between the treated and control ears occurred in both the apical and basal sections of the cochleae, we performed a two-way ANOVA (treatment $\times$ location) and found no significant interaction between the two factors $(F=$ $0.6, \mathrm{df}=1,92, p=0.441)$, suggesting that the decrease in sensory cell damage after doxycycline treatment occurs in both the apical and basal sections of the cochlear sensory epithelium. 
Together, these results suggest that doxycycline treatment potentiates hearing loss during the acute phase of noise-induced cochlear damage but reduces permanent hearing loss by conferring protection during the chronic phase of cochlear damage.

\section{Discussion}

MMPs and their related gene products are known to have crucial functions in many cellular processes and have been implicated in various neurological diseases. Here, we provide strong evidence for the involvement of these molecules in the maintenance of cochlear function and in the regulation of noise-induced cochlear damage. Our results suggest that an imbalance in MMPs is a detrimental factor for the induction of cochlear dysfunction. Importantly, our results suggest that the MMPs and their related gene products are novel therapeutic targets for the prevention of noise-induced cochlear dysfunction and sensory cell damage.

\section{Constitutive expression of MMPs and their related genes in the cochlear sensory epithelium}

The expression of MMPs and their related genes has been documented in a variety of tissue structures in the PNS and CNS (Wells et al., 2003; Weaver et al., 2005). In cochlear tissues, the expression of several MMP family members, including $M m p 2, M m p 9$, and Mmp14, have been identified (Reuter et al., 1998; Cho et al., 2002; Setz et al., 2011). Here, we used RNA-seq and qRT-PCR array techniques to profile the expression patterns and document the constitutive expression of a set of MMP genes, many of which have not been reported previously in the cochlear sensory epithelium. The detection of the strong, constitutive expression of multiple MMP genes in the cochlea provides the molecular basis for the prominent cochlear MMP activity observed in the current investigation. Interestingly, the TIMP genes are also highly expressed in the cochlea, suggesting that MMP activity is regulated by their intrinsic inhibitors under physiological conditions.

Our correlation analysis reveals a strong association between the expression levels of the MMPs and their related genes in the apical section and the basal section of the cochlear sensory epithelium. This result was anticipated, considering the fact that the two sections of the cochlear sensory epithelium contain the same populations of cells. However, comparison of the expression levels reveals that many of the examined genes were more highly expressed in the apical section than in the basal section. This type of difference was not observed for the other gene families in previous observations (Sato et al., 2009; Cai et al., 2012). Interestingly, the differences in the constitutive expression coincided with greater expression changes in the basal section of the cochlear sensory epithelium after acoustic trauma. It has been shown that the apical and basal sections of the cochlea differ in their frequency responses to acoustic stimuli (Robles and Ruggero, 2001). The two sections also exhibit different susceptibilities to various common pathological insults, including acoustic trauma, ototoxicity, and aging-related cochlear degeneration (Thorne et al., 1984; Bohne et al., 1987; Forge and Schacht, 2000; Sha et al., 2001; Hu et al., 2002; Pouyatos et al., 2009). Given the finding that the gene knock-out can lead to frequency-dependent hearing loss (Cheatham et al., 2004), we suspect that the sitenumber of cochleae.

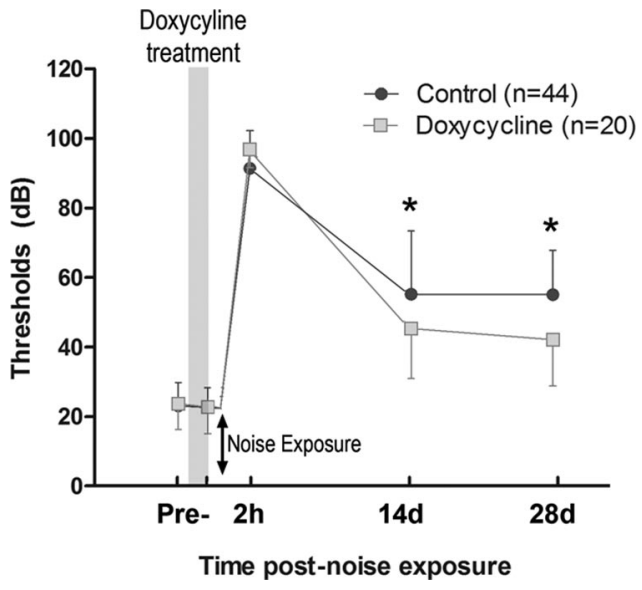

Figure 11. Comparison of the $A B R$ thresholds between the animals treated with or without doxycycline ( $50 \mathrm{mg} \cdot \mathrm{kg}^{-1} \cdot \mathrm{d}^{-1}$ for 3 doses in $1.5 \mathrm{~d}$ before the noise exposure). The shaded area represents the period of the doxycycline treatment. ${ }^{*} p<0.05$ (two-way ANOVA, Tukey's test). $n$ indicates the number of cochleae.

Figure 12. The effect of doxycycline treatment on noise-induced sensory cell damage. $\boldsymbol{A}$, Cochleogram showing the distribution of the missing sensory cells in the cochleae from the noise-exposed animals treated with or without doxycycline, as well as from the

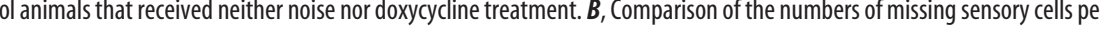
asterisk indicates the presence of a significant difference (Student's $t$ test, ${ }^{*} p<0.05$ ). Error bars indicate SD. $n$ indicates the

specific differences in the expression levels of MMPs and their related genes may serve as a contributing factor to the tonotopic differences in the function and biology of the two cochlear sections.

\section{MMPs and their related genes contribute to noise-induced cochlear degeneration}

Acoustic overstimulation causes cochlear dysfunction and sensory cell damage. Here, we provide strong evidence for the contribution of MMPs and their related gene products to acoustic injury. First, acoustic overstimulation resulted in time- and sitedependent transcriptional changes in MMPs and their related genes. Temporally, we observed that the changes in expression during the early phases of cochlear pathogenesis were dominated by upregulation and that the changes in expression during the later phase of cochlear pathogenesis were dominated by downregulation. This finding is consistent with the early increase in MMP expression that was observed in other traumatic injuries in the nervous system, including injury to the spinal cord (Wells et al., 2003; Veeravalli et al., 2009). Regarding the spatial pattern of the expression changes, our study shows that a greater change in expression occurs in the basal section of the cochlear sensory epithelium. This expression pattern is accompanied by greater sensory cell damage in the basal section of the cochlea (Cai et al., 
2012), highlighting the spatial correlation between these two events in the cochlear response to acoustic trauma.

The second piece of evidence linking the MMPs and their related genes to acoustic injury comes from the analysis of the protein expression pattern of TIMPs, the endogenous inhibitors of MMPs. We found an increase in the immunoreactivity of Timp1 and Timp2. Interestingly, these changes were spatially related to the cells that exhibited condensed or fragmented nuclei. Given that all of the cells that had condensed or fragmented nuclei exhibited strong immunoreactivity for Bax, a biological marker of apoptosis (Lalier et al., 2007), we believe that the alteration in TIMP protein expression is related to apoptotic cell damage and to permanent hearing loss. Here, we found that the numbers of Timp1/Timp2-positive cells are limited at the time of observation. Because the apoptotic process is a rapid cell death process, the presence of a limited number of positive cells at a given time point after noise exposure is expected. With the continuous growth of cochlear lesions after noise exposure, more cells will enter the apoptotic cell death pathway. Therefore, the total number of TIMP-positive cells is expected to be much higher than that observed. It should be noted that the change in Timp protein expression does not necessarily reflect a change in their enzymatic activity. Additional research on the changes in the activity of Timps is warranted.

The third piece of evidence for MMP participation in acoustic trauma involves changes in the enzymatic activity of MMPs. We found that the reduction in MMP activity was time-dependent and occurred at $1 \mathrm{~d}$ after injury. This type of dynamic change in MMP activity has been observed previously in non-cochlear tissues after traumatic injury and has been linked to the progression/recovery of tissue pathology (Wells et al., 2003; Kolar et al., 2008; Veeravalli et al., 2009). MMP activity is controlled at multiple levels, including transcriptional regulation, posttranslational modification, intrinsic inhibition, proenzyme activation, and MMP compartmentalization. In the current investigation, we examined two major regulatory mechanisms: the transcriptional expression of the MMP genes and the protein expression of the Timps. We found time-dependent changes in the expression levels of these proteins. To date, the molecular mechanisms responsible for the changes in expression of the MMPs are not clear. Studies using non-cochlear tissues have linked the regulation of MMP expression with nuclear binding factors, such as nuclear factor $\kappa \mathrm{B}$ and activator protein-1 (Overall et al., 2002). Both proteins have been linked to acoustic trauma (Ogita et al., 2000; Masuda et al., 2006). The presence of the complex regulatory mechanisms suggests that noise-induced cochlear damage is a multifactorial disorder.

Finally, we found that the inhibition of MMP activity compromised normal cochlear function, suggesting the importance of MMP activity in the maintenance of cochlear function. Moreover, the modulation of MMP expression and activity alters cochlear responses to acoustic overstimulation. The detailed molecular mechanisms responsible for this impact of MMPs are not clear. Recent studies have also shown that the MMPs have a variety of intracellular substrates (Sternlicht et al., 2001; Rodriguez et al., 2010). All of the MMPs that were found to be upregulated after noise exposure in the current study have implications for the range of intracellular substrates accessible to these MMPs (Golubkov et al., 2005; Choi et al., 2008; Cuadrado et al., 2009). Given the detection of expression changes in multiple MMPs and their related genes, we suspect that the observed effects are orchestrated by the integrated action of MMP molecules. Together, the observation of changes in the levels of enzymatic activity, protein expression, and transcriptional expression indicates that the MMPs and their related genes are involved in the regulation of the cochlear response to acoustic overstimulation.
This observation is the first to link the MMPs and their related genes to acute acoustic trauma.

\section{Therapeutic implications of MMP inhibition}

The regulation of acoustic trauma through MMPs raises the possibility of using MMP intervention as a therapeutic strategy to reduce noise-induced cochlear damage. Here, we reveal two features associated with doxycycline treatment. First, a short-term treatment before acoustic trauma is protective, whereas prolonged treatment potentiates noise-induced hearing loss. This finding is supported by the data from the experiment using $M m p 7^{-1-}$ mice. Second, the protection of hearing induced by the doxycycline treatment manifested after the completion of the drug treatment rather than during the treatment. These observations suggest that the timing of MMP intervention is an important factor that contributes to the ultimate outcome of the intervention. It should be noted that the biological effects of doxycycline are complex. Although this drug has been widely used for modulating MMP activity, it can exert other biological impacts, including anti-inflammation (Krakauer et al., 2003). To this end, future investigations using more specific MMP inhibitors are expected to provide more insights into the effects of MMP intervention on noise-induced cochlear damage.

\section{References}

Bedi A, Fox AJ, Kovacevic D, Deng XH, Warren RF, Rodeo SA (2010) Doxycycline-mediated inhibition of matrix metalloproteinases improves healing after rotator cuff repair. Am J Sports Med 38:308-317.

Birkedal-Hansen H, Moore WG, Bodden MK, Windsor LJ, Birkedal-Hansen B, DeCarlo A, Engler JA (1993) Matrix metalloproteinases: a review. Crit Rev Oral Biol Med 4:197-250.

Bohne BA, Yohman L, Gruner MM (1987) Cochlear damage following interrupted exposure to high-frequency noise. Hear Res 29:251-264.

Bohne BA, Harding GW, Lee SC (2007) Death pathways in noise-damaged outer hair cells. Hear Res 223:61-70.

Burggraf D, Trinkl A, Dichgans M, Hamann GF (2007) Doxycycline inhibits MMPs via modulation of plasminogen activators in focal cerebral ischemia. Neurobiol Dis 25:506-513.

Cai Q, Patel M, Coling D, Hu BH (2012) Transcriptional changes in adhesion-related genes are site-specific during noise-induced cochlear pathogenesis. Neurobiol Dis 45:723-732.

Canlon B (1987) Acoustic overstimulation alters the morphology of the tectorial membrane. Hear Res 30:127-134.

Canlon B (1988) The effect of acoustic trauma on the tectorial membrane, stereocilia, and hearing sensitivity: possible mechanisms underlying damage, recovery, and protection. Scand Audiol Suppl 27:1-45.

Cheatham MA, Huynh KH, Gao J, Zuo J, Dallos P (2004) Cochlear function in Prestin knockout mice. J Physiol 560:821-830.

Cho Y, Gong TW, Stöver T, Lomax MI, Altschuler RA (2002) Gene expression profiles of the rat cochlea, cochlear nucleus, and inferior colliculus. J Assoc Res Otolaryngol 3:54-67.

Choi DH, Kim EM, Son HJ, Joh TH, Kim YS, Kim D, Flint Beal M, Hwang O (2008) A novel intracellular role of matrix metalloproteinase-3 during apoptosis of dopaminergic cells. J Neurochem 106:405-415.

Clark WM, Lessov N, Lauten JD, Hazel K (1997) Doxycycline treatment reduces ischemic brain damage in transient middle cerebral artery occlusion in the rat. J Mol Neurosci 9:103-108.

Consolo M, Amoroso A, Spandidos DA, Mazzarino MC (2009) Matrix metalloproteinases and their inhibitors as markers of inflammation and fibrosis in chronic liver disease (review). Int J Mol Med 24:143-152.

Cuadrado E, Rosell A, Borrell-Pages M, Garcia-Bonilla L, HernandezGuillamon M, Ortega-Aznar A, Montaner J (2009) Matrix metalloproteinase-13 is activated and is found in the nucleus of neural cells after cerebral ischemia. J Cereb Blood Flow Metab 29:398-410.

Curci JA, Petrinec D, Liao S, Golub LM, Thompson RW (1998) Pharmacologic suppression of experimental abdominal aortic aneurysms: acomparison of doxycycline and four chemically modified tetracyclines. J Vasc Surg 28:1082-1093.

Davies D, Magnus C, Corwin JT (2007) Developmental changes in cell- 
extracellular matrix interactions limit proliferation in the mammalian inner ear. Eur J Neurosci 25:985-998.

Forge A, Schacht J (2000) Aminoglycoside antibiotics. Audiol Neurootol 5:3-22.

Fredrich M, Illing RB (2010) MMP-2 is involved in synaptic remodeling after cochlear lesion. Neuroreport 21:324-327.

Fujita PA, Rhead B, Zweig AS, Hinrichs AS, Karolchik D, Cline MS, Goldman M, Barber GP, Clawson H, Coelho A, Diekhans M, Dreszer TR, Giardine BM, Harte RA, Hillman-Jackson J, Hsu F, Kirkup V, Kuhn RM, Learned K, Li CH, Meyer LR, Pohl A, Raney BJ, Rosenbloom KR, Smith KE, Haussler D, Kent WJ (2011) The UCSC Genome Browser database: update 2011. Nucleic Acids Res 39:D876-D882.

Golubkov VS, Boyd S, Savinov AY, Chekanov AV, Osterman AL, Remacle A, Rozanov DV, Doxsey SJ, Strongin AY (2005) Membrane type-1 matrix metalloproteinase (MT1-MMP) exhibits an important intracellular cleavage function and causes chromosome instability. J Biol Chem 280:25079-25086.

Gratton MA, Rao VH, Meehan DT, Askew C, Cosgrove D (2005) Matrix metalloproteinase dysregulation in the stria vascularis of mice with Alport syndrome: implications for capillary basement membrane pathology. Am J Pathol 166:1465-1474.

Greenwald RA, Golub LM, Ramamurthy NS, Chowdhury M, Moak SA, Sorsa $\mathrm{T}$ (1998) In vitro sensitivity of the three mammalian collagenases to tetracycline inhibition: relationship to bone and cartilage degradation. Bone 22:33-38.

Gulley RL, Reese TS (1976) Intercellular junctions in the reticular lamina of the organ of Corti. J Neurocytol 5:479-507.

Han W, Shi X, Nuttall AL (2006) AIF and endoG translocation in noise exposure induced hair cell death. Hear Res 211:85-95.

Hanemaaijer R, Visser H, Koolwijk P, Sorsa T, Salo T, Golub LM, van Hinsbergh VW (1998) Inhibition of MMP synthesis by doxycycline and chemically modified tetracyclines (CMTs) in human endothelial cells. Adv Dent Res 12:114-118.

Henderson D, Bielefeld EC, Harris KC, Hu BH (2006) The role of oxidative stress in noise-induced hearing loss. Ear Hear 27:1-19.

Hu B (2012) Noise-induced structural damage to the cochlea. In: Noiseinduced hearing loss—scientific advances (Le Prell CG, Henderson D, Fay RR, Popper AN, eds), pp 57-86. New York: Springer.

Hu BH, Cai Q (2010) Acoustic overstimulation modifies Mcl-1 expression in cochlear sensory epithelial cells. J Neurosci Res 88:1812-1821.

Hu BH, Guo W, Wang PY, Henderson D, Jiang SC (2000) Intense noiseinduced apoptosis in hair cells of guinea pig cochleae. Acta Otolaryngol 120:19-24.

Hu BH, Henderson D, Nicotera TM (2002) Involvement of apoptosis in progression of cochlear lesion following exposure to intense noise. Hear Res 166:62-71.

Hu BH, Henderson D, Nicotera TM (2006) Extremely rapid induction of outer hair cell apoptosis in the chinchilla cochlea following exposure to impulse noise. Hear Res 211:16-25.

Hu BH, Cai Q, Manohar S, Jiang H, Ding D, Coling DE, Zheng G, Salvi R (2009) Differential expression of apoptosis-related genes in the cochlea of noise-exposed rats. Neuroscience 161:915-925.

Kolar M, Pachl J, Tomasova H, Haninec P (2008) Dymanics of matrixmetalloproteinase 9 after brain trauma-results of a pilot study. Acta Neurochir Suppl 102:373-376.

Krakauer T, Buckley M (2003) Doxycycline is anti-inflammatory and inhibits staphylococcal exotoxin-induced cytokines and chemokines. Antimicrob Agents Chemother 47:3630-3633.

Kundu S, Tyagi N, Sen U, Tyagi SC (2009) Matrix imbalance by inducing expression of metalloproteinase and oxidative stress in cochlea of hyperhomocysteinemic mice. Mol Cell Biochem 332:215-224.

Lalier L, Cartron PF, Juin P, Nedelkina S, Manon S, Bechinger B, Vallette FM (2007) Bax activation and mitochondrial insertion during apoptosis. Apoptosis 12:887-896.

Langmead B, Trapnell C, Pop M, Salzberg SL (2009) Ultrafast and memoryefficient alignment of short DNA sequences to the human genome. Genome Biol 10:R25.

Lee CZ, Xu B, Hashimoto T, McCulloch CE, Yang GY, Young WL (2004) Doxycycline suppresses cerebral matrix metalloproteinase- 9 and angiogenesis induced by focal hyperstimulation of vascular endothelial growth factor in a mouse model. Stroke 35:1715-1719.

Lee HM, Golub LM, Cao J, Teronen O, Laitinen M, Salo T, Zucker S, Sorsa T
(2001) CMT-3, a non-antimicrobial tetracycline (TC), inhibits MT1MMP activity: relevance to cancer. Curr Med Chem 8:257-260.

Livak KJ, Schmittgen TD (2001) Analysis of relative gene expression data using real-time quantitative PCR and the 2(-Delta Delta $\mathrm{C}(\mathrm{T})$ ) method. Methods 25:402-408.

Masuda M, Nagashima R, Kanzaki S, Fujioka M, Ogita K, Ogawa K (2006) Nuclear factor-kappa B nuclear translocation in the cochlea of mice following acoustic overstimulation. Brain Res 1068:237-247.

McCawley LJ, Matrisian LM (2001) Matrix metalloproteinases: they're not just for matrix anymore! Curr Opin Cell Biol 13:534-540.

Mortazavi A, Williams BA, McCue K, Schaeffer L, Wold B (2008) Mapping and quantifying mammalian transcriptomes by RNA-Seq. Nat Methods 5:621-628.

Müller M (1991) Frequency representation in the rat cochlea. Hear Res 51:247-254

Nam SI, Yu GI, Kim HJ, Park KO, Chung JH, Ha E, Shin DH (2011) A polymorphism at $-16072 \mathrm{G}$ in the matrix metalloproteinase-1 (MMP-1) increased risk of sudden deafness in Korean population but not at -519A/G in MMP-1. Laryngoscope 121:171-175.

Niu X, Shao R, Canlon B (2003) Suppression of apoptosis occurs in the cochlea by sound conditioning. Neuroreport 14:1025-1029.

Nogueira CR, Damasceno FM, de Aquino-Neto MR, de Andrade GM, Fontenele JB, de Medeiros TA, Viana GS (2011) Doxycycline protects against pilocarpine-induced convulsions in rats, through its antioxidant effect and modulation of brain amino acids. Pharmacol Biochem Behav 98:525-532.

Ogita K, Matsunobu T, Schacht J (2000) Acoustic trauma enhances DNA binding of transcription factor AP-1 in the guinea pig inner ear. Neuroreport 11:859-862.

Overall CM, Lopez-Otin C (2002) Strategies for MMP inhibition in cancer: innovations for the post-trial era. Nature Rev Cancer 2:657-672.

Page-McCaw A, Ewald AJ, Werb Z (2007) Matrix metalloproteinases and the regulation of tissue remodelling. Nat Rev Mol Cell Biol 8:221-233.

Pagenstecher A, Stalder AK, Kincaid CL, Volk B, Campbell IL (2000) Regulation of matrix metalloproteinases and their inhibitor genes in lipopolysaccharide-induced endotoxemia in mice. Am J Pathol 157: 197-210.

Parks WC, Wilson CL, López-Boado YS (2004) Matrix metalloproteinases as modulators of inflammation and innate immunity. Nat Rev Immunol 4:617-629.

Pouyatos B, Gearhart CA, Nelson-Miller A, Fulton S, Fechter LD (2009) Selective vulnerability of the cochlear basal turn to acrylonitrile and noise. J Toxicol 2009:908596

Raphael Y, Altschuler RA (1991) Reorganization of cytoskeletal and junctional proteins during cochlear hair cell degeneration. Cell Motil Cytoskeleton 18:215-227.

Raphael Y, Volk T, Crossin KL, Edelman GM, Geiger B (1988) The modulation of cell adhesion molecule expression and intercellular junction formation in the developing avian inner ear. Dev Biol 128:222-235.

Raphael Y, Athey BD, Wang Y, Hawkins JE Jr (1993) Structure of the reticular lamina and repair after noise injury. Rev Laryngol Otol Rhinol (Bord) 114:171-175.

Ravanti L, Kähäri VM (2000) Matrix metalloproteinases in wound repair (review). Int J Mol Med 6:391-407.

Reuter A, Nestl A, Zwacka RM, Tuckermann J, Waldherr R, Wagner EM, Hoyhtya M, Meyer zum Gottesberge AM, Angel P, Weiher H (1998) Expression of the recessive glomerulosclerosis gene Mpv17 regulates MMP-2 expression in fibroblasts, the kidney, and the inner ear of mice. Mol Biol Cell 9:1675-1682.

Robles L, Ruggero MA (2001) Mechanics of the mammalian cochlea. Physiol Rev 81:1305-1352.

Rodriguez D, Morrison CJ, Overall CM (2010) Matrix metalloproteinases: what do they not do? New substrates and biological roles identified by murine models and proteomics. Biochim Biophys Acta 1803:39-54.

Sato T, Doi K, Hibino H, Kubo T (2009) Analysis of gene expression profiles along the tonotopic map of mouse cochlea by cDNA microarrays. Acta Otolaryngol Suppl:12-17.

Saunders JC, Dear SP, Schneider ME (1985) The anatomical consequences of acoustic injury: a review and tutorial. J Acoust Soc Am 78:833-860.

Setz C, Brand Y, Radojevic V, Hanusek C, Mullen PJ, Levano S, Listyo A, Bodmer D (2011) Matrix metalloproteinases 2 and 9 in the cochlea: 
expression and activity after aminoglycoside exposition. Neuroscience 181:28-39.

Sha SH, Taylor R, Forge A, Schacht J (2001) Differential vulnerability of basal and apical hair cells is based on intrinsic susceptibility to free radicals. Hear Res 155:1-8.

Shibuya H, Kato Y, Saito M, Isobe T, Tsuboi R, Koga M, Toyota H, Mizuguchi J (2003) Induction of apoptosis and/or necrosis following exposure to antitumour agents in a melanoma cell line, probably through modulation of Bcl-2 family proteins. Melanoma Res 13:457-464.

Shlopov BV, Stuart JM, Gumanovskaya ML, Hasty KA (2001) Regulation of cartilage collagenase by doxycycline. J Rheumatol 28:835-842.

Stankovic KM, Corfas G (2003) Real-time quantitative RT-PCR for lowabundance transcripts in the inner ear: analysis of neurotrophic factor expression. Hear Res 185:97-108.

Sternlicht MD, Werb Z (2001) How matrix metalloproteinases regulate cell behavior. Annu Rev Cell Dev Biol 17:463-516.

Szabova L, Son MY, Shi J, Sramko M, Yamada SS, Swaim WD, Zerfas P, Kahan S, Holmbeck K (2010) Membrane-type MMPs are indispensable for placental labyrinth formation and development. Blood 116: 5752-5761.

Thorne PR, Gavin JB, Herdson PB (1984) A quantitative study of the sequence of topographical changes in the organ of Corti following acoustic trauma. Acta Otolaryngol 97:69-81.

Trapnell C, Pachter L, Salzberg SL (2009) TopHat: discovering splice junctions with RNA-Seq. Bioinformatics 25:1105-1111.

Trapnell C, Williams BA, Pertea G, Mortazavi A, Kwan G, van Baren MJ, Salzberg SL, Wold BJ, Pachter L (2010) Transcript assembly and quantification by RNA-Seq reveals unannotated transcripts and isoform switching during cell differentiation. Nat Biotechnol 28:511-515.
Tsuprun V, Santi P (1999) Ultrastructure and immunohistochemical identification of the extracellular matrix of the chinchilla cochlea. Hear Res 129:35-49.

Tusher VG, Tibshirani R, Chu G (2001) Significance analysis of microarrays applied to the ionizing radiation response. Proc Natl Acad Sci U S A 98:5116-5121.

Veeravalli KK, Dasari VR, Tsung AJ, Dinh DH, Gujrati M, Fassett D, Rao JS (2009) Human umbilical cord blood stem cells upregulate matrix metalloproteinase-2 in rats after spinal cord injury. Neurobiology of disease 36:200-212.

Wang J, Dib M, Lenoir M, Vago P, Eybalin M, Hameg A, Pujol R, Puel JL (2002) Riluzole rescues cochlear sensory cells from acoustic trauma in the guinea-pig. Neuroscience 111:635-648.

Weaver A, Goncalves da Silva A, Nuttall RK, Edwards DR, Shapiro SD, Rivest S, Yong VW (2005) An elevated matrix metalloproteinase (MMP) in an animal model of multiple sclerosis is protective by affecting Th1/Th2 polarization. FASEB J 19:1668-1670.

Wells JE, Rice TK, Nuttall RK, Edwards DR, Zekki H, Rivest S, Yong VW (2003) An adverse role for matrix metalloproteinase 12 after spinal cord injury in mice. J Neurosci 23:10107-10115.

Yang WP, Henderson D, Hu BH, Nicotera TM (2004) Quantitative analysis of apoptotic and necrotic outer hair cells after exposure to different levels of continuous noise. Hear Res 196:69-76.

Ylikoski J, Xing-Qun L, Virkkala J, Pirvola U (2002) Blockade of c-Jun $\mathrm{N}$-terminal kinase pathway attenuates gentamicin-induced cochlear and vestibular hair cell death. Hear Res 166:33-43.

Yong VW (2005) Metalloproteinases: mediators of pathology and regeneration in the CNS. Nat Rev Neurosci 6:931-944. 